\title{
Fibroblast Growth Factor-23-Klotho Axis in Cardiorenal Syndrome: Mediators and Potential Therapeutic Targets
}

\begin{abstract}
José Alberto Navarro-García ${ }^{1 *}$, Laura González-Lafuente', Maria Fernández-Velasco², Luis M. Ruilope ${ }^{1,3,4}$ and Gema Ruiz-Hurtado ${ }^{1,3 *}$

'Cardiorenal Translational Laboratory, Institute of Research i + 12, Hospital Universitario 12 de Octubre, Madrid, Spain, ${ }^{2}$ IdiPAZ Institute for Health Research/CIBER-CV, Hospital Universitario La Paz, Madrid, Spain, ${ }^{3}$ CIBER-CV, Hospital Universitario 12 de Octubre, Madrid, Spain, ${ }^{4}$ School of Doctoral Studies and Research, European University of Madrid, Madrid, Spain
\end{abstract}

OPEN ACCESS

Edited by:

Belisario Enrique Fernandez, University Institute of Health Sciences, Argentina

Reviewed by:

Silvana Lorena Della Penna, University of New South Wales, Australia

Ana María Puyó, University of Buenos Aires, Argentina Germán González,

Consejo Nacional de Investigaciones Científicas y Técnicas (CONICET),

Argentina

*Correspondence

José Alberto Navarro-García jalbertong@gmail.com

Gema Ruiz-Hurtado gemaruiz@h12o.es

Specialty section:

This article was submitted to Renal and Epithelial Physiology,

a section of the journal

Frontiers in Physiology

Received: 13 September 2021

Accepted: 25 October 2021

Published: 15 November 2021

Citation:

Navarro-García JA,

González-Lafuente L,

Fernández-Velasco M, Ruilope $L M$ and Ruiz-Hurtado G (2021) Fibroblast

Growth Factor-23-Klotho Axis in Cardiorenal Syndrome: Mediators and Potential Therapeutic Targets. Front. Physiol. 12:775029 doi: 10.3389/fphys.2021.775029
Cardiorenal syndrome (CRS) is a complex disorder that refers to the category of acute or chronic kidney diseases that induce cardiovascular disease, and inversely, acute or chronic heart diseases that provoke kidney dysfunction. There is a close relationship between renal and cardiovascular disease, possibly due to the presence of common risk factors for both diseases. Thus, it is well known that renal diseases are associated with increased risk of developing cardiovascular disease, suffering cardiac events and even mortality, which is aggravated in those patients with end-stage renal disease or who are undergoing dialysis. Recent works have proposed mineral bone disorders (MBD) as the possible link between kidney dysfunction and the development of cardiovascular outcomes. Traditionally, increased serum phosphate levels have been proposed as one of the main factors responsible for cardiovascular damage in kidney patients. However, recent studies have focused on other MBD components such as the elevation of fibroblast growth factor (FGF)-23, a phosphaturic bone-derived hormone, and the decreased expression of the anti-aging factor Klotho in renal patients. It has been shown that increased FGF-23 levels induce cardiac hypertrophy and dysfunction and are associated with increased cardiovascular mortality in renal patients. Decreased Klotho expression occurs as renal function declines. Despite its expression being absent in myocardial tissue, several studies have demonstrated that this antiaging factor plays a cardioprotective role, especially under elevated FGF-23 levels. The present review aims to collect the recent knowledge about the FGF-23-Klotho axis in the connection between kidney and heart, focusing on their specific role as new therapeutic targets in CRS.

Keywords: FGF-23, Klotho, cardiorenal syndrome, chronic kidney disease, acute kidney injury, dialysis, heart failure

\section{INTRODUCTION}

Cardiorenal syndrome (CRS) is defined as a complex pathological disorder that involves the kidneys and heart, whereby acute or chronic dysfunction in one organ may induce acute or chronic dysfunction in the other (Ronco et al., 2010). The presence of both cardiovascular and renal disease increases the risk of suffering cardiovascular events and death, even after adjustment for traditional 
cardiovascular risk factors (Gansevoort et al., 2013). Depending on the origin of the pathology, CRS can be classified into five different subtypes: acute CRS, whether the acute worsening of the heart function leads to a renal dysfunction or kidney injury (type 1 CRS or CRS1); chronic CRS, where the chronic heart dysfunction induces renal dysfunction or kidney injury (type 2 CRS or CRS2); acute reno-cardiac syndrome, which is an acute kidney injury (AKI) that leads to a heart dysfunction (type 3 CRS or CRS3); chronic reno-cardiac syndrome, when the existence of chronic kidney disease (CKD) leads to heart dysfunction (type 4 CRS or CRS4); and secondary CRS, where another pathology induces the development of heart and kidney disease simultaneously (type 5 CRS or CRS5) (Ronco et al., 2010).

\section{CARDIOVASCULAR EVENTS AND MORTALITY IN RENAL DISEASE}

It is well established that renal disease is associated with a high risk of cardiovascular disease (Gansevoort et al., 2013; Legrand and Rossignol, 2020). Compared to the healthy population, renal patients present greater all-cause and cardiovascular mortality (van der Velde et al., 2011; Odutayo et al., 2017), especially end-stage renal disease (ESRD) patients (de Jager et al., 2009). Thus, more than $50 \%$ of renal patients die due to cardiovascular complications even before reaching ESRD. Premature deaths are also very common before and during dialysis cycles (Go et al., 2004), with a 10-20-fold greater cardiovascular mortality risk in dialysis patients than in the general population (de Jager et al., 2009). This increased cardiovascular mortality might be linked to the fact that more than half of ESRD patients develop cardiac arrhythmias (Hsieh et al., 2020; Kim et al., 2021) or heart failure (HF) (House et al., 2019). Renal patients usually develop left ventricular hypertrophy (LVH) (Middleton et al., 2001), atrial fibrillation (AF) (Hsieh et al., 2020), HF (Schefold et al., 2016; Odutayo et al., 2017), ischemic heart disease, and ventricular tachycardia (Kim et al., 2021) which are related to increased risk of mortality in these patients. In this context, there are some kidney disease-related pro-arrhythmogenic risk factors that might predispose these patients to suffer arrhythmias and cardiac structure alterations such as variation in fluxes of key electrolytes, metabolic acidosis, and the presence of uremic toxins (Tang et al., 2015; Di Lullo et al., 2019).

On the other hand, the two main factors that define renal disease-albuminuria and decreased estimated glomerular filtration rate (eGFR) - are both independent risk factors for the prediction of cardiovascular events and death (van der Velde et al., 2011; Gansevoort et al., 2013). Thus, lower eGFR and higher albumin-to-creatinine ratio (ACR) have been associated with a significant increment to cardiovascular mortality (Ruilope and Bakris, 2011; van der Velde et al., 2011; Gansevoort et al., 2013). Both eGFR and ACR values are even more useful than other traditional risk factors as predictors of incident cardiovascular events such as HF (Matsushita et al., 2015). In addition, as renal function declines, new risk factors appear that contribute to renal dysfunction while also increasing the risk of cardiovascular damage (Ruilope and Bakris, 2011). Among these are biological aging, hypertension, diabetes mellitus, atherosclerosis, endothelial dysfunction, accumulation of uremic toxins, and mineral bone disorders (MBDs) (Ruiz-Hurtado and Ruilope, 2014; Ruiz-Hurtado et al., 2016). The development of cardiovascular disease associated with the uremic milieu is named uremic cardiomyopathy. Uremic cardiomyopathy was first described in Bailey et al. (1967) who observed cardiac hypertrophy and its relation with diet in CKD patients with highly increased creatinine and urea serum levels. Despite the clear clinical association between kidney failure and cardiac damage and vice versa, the underlying mechanisms connecting both systems are not well understood.

\section{Left Ventricular Hypertrophy}

$\mathrm{LVH}$ is one of the most common cardiac alterations described in renal patients (Middleton et al., 2001; Faul et al., 2011). LVH can be associated with ischemic heart disease, diastolic dysfunction, and a decompensated situation that can induce HF over the long-term (Harnett et al., 1995), as it increases the probability of cardiac arrhythmias (Rantanen et al., 2020) that are associated with a decreased survival rate in renal patients (Banerjee, 2016). The development of LVH in renal patients might be the consequence of maintained pressure overload and hypertension, both of which are frequently observed in these patients. Shen et al. (2020) recently proposed cystatin C secretion by cardiomyocytes in response to pressure overload as a possible promoter of cardiac hypertrophy in renal patients. Other studies have focused on the alteration of mineral bone components in renal patients as an important factor in the development of $\mathrm{LVH}$, describing a direct pro-hypertrophic effect of fibroblast growth factor (FGF)23 on the heart (Faul et al., 2011). However, other authors have proposed the FGF-23-mediated activation of the cardiac renin-angiotensin-aldosterone system (RAAS) as the inductor of cardiac hypertrophy and fibrosis in renal patients (Böckmann et al., 2019). More studies are needed to elucidate which of these factors is the early inducer of cardiac hypertrophy in renal patients; that will facilitate the determination of whether there is a main causative factor, or whether it is the combination of all factors that is responsible for the deleterious cardiac remodeling.

\section{Heart Failure}

$\mathrm{HF}$ is the main cardiovascular complication and the leading cause of mortality in renal patients (Tuegel and Bansal, 2017; Go et al., 2018), especially in ESRD patients (Bansal et al., 2017). HF consists of the heart inability to supply the peripheral tissue demands with enough blood and oxygen. HF patients are divided according to the ejection fraction (EF) as patients with systolic HF, who present reduced EF (HF-rEF), and patients with diastolic HF, with preserved systolic function but compromised diastolic function (preserved EF, HF-pEF). HF-rEF is a consequence of an impairment of left ventricular contractility, usually linked to eccentric remodeling with chamber dilatation. By contrast, HF$\mathrm{pEF}$ is characterized by an impaired ventricular relaxation and filling as consequence of the concentric remodeling. In most cases, HF appears due to a subjacent myocardial disease as consequence of a myocardial ischemia. However, HF can also be developed from a concomitant disease such as renal disease. In 
this line, the risk of HF development significantly increases in AKI patients over the long term (Gammelager et al., 2014; Go et al., 2018). It has been described that stage 3 CKD patients present a threefold higher risk of HF development compared to healthy population (Kottgen et al., 2007). CKD patients can develop either diastolic or systolic HF. It has been found that the majority of ESRD patients display HF-pEF with diastolic dysfunction and presence of LVH, while HF-rEF is visible only in the minority of these patients (Antlanger et al., 2017). Notably, it is the HF-pEF phenotype that represents a higher mortality risk in renal patients (Ahmed et al., 2007). It is further important to remark that HF development begins even in the early stages of CKD. Indeed, assessment of a large group of HF patients has shown that diastolic dysfunction, systolic dysfunction, and mortality increased in parallel with the progression of CKD (Unger et al., 2016). This might be explained by the fact that $\mathrm{HF}$ is a status of low cardiac output that diminishes the effective glomerular filtration pressure, decreasing eGFR and promoting the development or progression of CKD. At the experimental level, a significant reduction in EF was observed in CKD mice following 5/6 nephrectomy (Navarro-García et al., 2020). In an experimental AKI model, mice developed diastolic dysfunction with reduced EF (Hu et al., 2017). However, other authors have shown more recently that AKI mice develop HF with preserved EF (Fox et al., 2019; Soranno et al., 2021). In spite of the differences observed, which are possibly based on the method used to induce renal disease and the time of renal damage progression, renal disease mouse models have clearly shown HF development. It is likely that kidney dysfunction not only plays an important causative role in the development and progression of HF, but also acts as a marker of HF severity.

\section{Arrhythmias}

In dialysis patients, arrhythmia is a common symptom frequently observed in the inter-dialytic interval (Roy-Chaudhury et al., 2018). Bradycardias and asystole are the more common arrhythmias described in the inter-dialytic interval, while ventricular tachycardia and AF have been found during the dialysis procedure (Roy-Chaudhury et al., 2018; Hsieh et al., 2020). However, it is not easy to determine the main factor triggering the arrhythmia responsible for sudden cardiac death (SCD) in dialysis patients; this is because SCD usually happens outside of the dialysis unit during the inter-dialytic interval. As ventricular arrhythmia is possibly the main cause of SCD in the general population (Priori et al., 2001), this fatal event might be linked to the high prevalence of cardiac deaths found in CKD and ESRD patients (Genovesi et al., 2013; Coll et al., 2018). Recent studies have pointed to FGF-23 as an important inducer factor of ventricular arrhythmias (Navarro-García et al., 2019).

\section{MINERAL BONE DISORDERS AND CARDIORENAL SYNDROME}

Mineral metabolism disturbances are closely connected with both AKI (Leaf and Christov, 2019) and CKD (Rouached et al., 2008). MBDs contribute to the augmented morbidity and mortality observed in renal patients (Block et al., 2004). MBD is aggravated with the decrease of renal function. MBDs include changes in serum calcium $\left(\mathrm{Ca}^{2+}\right)$ concentration, increased serum phosphate levels (hyperphosphatemia), reduced serum levels of active vitamin $\mathrm{D}$, secondary increase of parathyroid hormone (PTH), augmented FGF-23 systemic levels, and reduced levels of the antiaging factor Klotho (Wang et al., 2018). Mineral bone components are regulated by important negative and positive feedback loops between them (Navarro-García et al., 2018). Thus, the systemic levels of any one of these components depend on the levels of the others, with the objective of maintaining an adequate phosphate and $\mathrm{Ca}^{2+}$ homeostasis. However, the loss of renal function disrupts these feedback loops. Moreover, changes in any one of these parameters misbalance the feedback loops, altering the circulating levels of the others and inducing significant effects on remote organs such as the heart. In the context of renal disease, the increased levels of phosphate, increased $\mathrm{PTH}$, vitamin D deficiency, Klotho deficiency, and augmented FGF-23 levels might facilitate cardiovascular events, including structural alterations like LVH (Faul et al., 2011), cardiac dysfunction such as HF (Wannamethee et al., 2014), and rhythm alterations such as AF (Mathew et al., 2014) or ventricular arrhythmia (NavarroGarcía et al., 2019, 2020).

\section{Vitamin D and Parathyroid Hormone}

$\mathrm{Ca}^{2+}$ homeostasis is chiefly regulated by $1,25-$ dihydroxycholecalciferol D3 (or vitamin D) and PTH. A reduction of serum $\mathrm{Ca}^{2+}$ concentration activates the synthesis of PTH in the parathyroid gland. PTH binds to PTH receptors (PTHR) in the kidney, stimulating $\mathrm{Ca}^{2+}$ reabsorption but also increasing vitamin $\mathrm{D}$ synthesis. Vitamin $\mathrm{D}$ binds to vitamin $\mathrm{D}$ receptors (VDR) on the surface of enterocytes in the intestinal tract, increasing dietary $\mathrm{Ca}^{2+}$ absorption by augmenting the expression of the transient receptor potential cation channel subfamily $\mathrm{V}$ member 6 and plasma membrane $\mathrm{Ca}^{2+}$-ATPase (Christakos et al., 2010). Furthermore, the binding of vitamin $\mathrm{D}$ to VDR of the parathyroid gland inhibits PTH synthesis, which constitutes an important feedback mechanism related to $\mathrm{Ca}^{2+}$ homeostasis (Navarro-García et al., 2018). The loss of renal function is frequently related to vitamin $\mathrm{D}$ deficiency (Wolf, 2010) and increased synthesis of PTH (secondary hyperparathyroidism) (Madsen et al., 1981; Naveh-Many and Volovelsky, 2020).

Reduced serum vitamin D levels in renal patients arise due to impaired activity of the renal enzyme 1- $\alpha$-hydroxylase, which transforms 25-hydroxyvitamin D3 into the active hormone form of vitamin D, 1,25-dihydroxycholecalciferol D3. However, vitamin D and PTH are not only important for $\mathrm{Ca}^{2+}$ homeostasis, but also play an important role in phosphate homeostasis. Serum PTH acts on type II sodium/phosphate cotransporters to reduce renal phosphate reabsorption (Kronenberg, 2002). At the gut level, vitamin D binding to VDR on enterocytes also increases the expression of the sodium-dependent phosphate transporter Pit-2, facilitating phosphate absorption (Katai et al., 1999). It is well known that changes in both vitamin D and PTH are related to important cardiovascular alterations, especially in renal patients. Thus, 
vitamin D deficiency has been linked to a higher risk of cardiac hypertrophy, LV dysfunction, HF development and mortality (Bodyak et al., 2007; Anderson et al., 2010; Gotsman et al., 2012). In this line, several studies have demonstrated that treatment with vitamin $\mathrm{D}$ analogs such as paricalcitol can reduce vascular calcification (Anis et al., 2020) and LVH (Bodyak et al., 2007; Leifheit-Nestler et al., 2017) under uremic conditions. Moreover, paricalcitol treatment has also been shown to impede the progression of $\mathrm{HF}$ by improving adverse $\mathrm{Ca}^{2+}$ mishandling even in the absence of renal disease (Tamayo et al., 2020). In addition, PTH disorders have been related to hypertension, valve calcification, HF (Khouzam et al., 2006), arrhythmias (Curione et al., 2010), and mortality in renal patients (Molina et al., 2021).

\section{Phosphates}

Systemic phosphate levels appear to increase in renal patients due to the loss of renal function (Jung et al., 2018; Bacchetta et al., 2020). High phosphate levels have been related to mortality in renal patients (Merhi et al., 2017; Moon et al., 2019), mainly in those undergoing dialysis (Owaki et al., 2018), but also in the general population (Chang and Grams, 2014). Phosphate homeostasis depends on the counterbalance between dietary phosphate intake, phosphate mobilization from bone, and renal phosphate excretion. Thus, renal dysfunction carries an important increment of serum phosphate levels. Classically, serum phosphates levels have been considered the main cause of increased risk of cardiovascular disease among renal patients, including the higher risk of mortality (Palmer et al., 2011; Scialla and Wolf, 2014; Moon et al., 2019). Phosphates have been described as promoting vascular calcification in renal patients (Cozzolino et al., 2019). Furthermore, phosphate levels have been linked to left ventricular remodeling in renal patients (Zou et al., 2016).

\section{Fibroblast Growth Factor-23}

The main physiological regulator of serum phosphate levels is FGF-23, which acts as a phosphaturic hormone (Seiler et al., 2009). Phosphates have traditionally been established as the main target to control in renal disease, with FGF-23 having been considered a "secondary player" that has the apparently unique role of reducing serum phosphate levels. However, FGF-23 has recently emerged as a new and direct factor in the context of cardiac damage. It has accordingly been described that increased FGF-23 levels are the first alteration observed in renal patients, even earlier than elevated phosphate serum levels (Wolf, 2012; Christov et al., 2013). FGF-23 is a hormone mainly synthesized by osteocytes and osteoblasts in long bones to control phosphate homeostasis and serum levels of vitamin D and PTH (NavarroGarcía et al., 2018). The principal stimulus for FGF-23 synthesis is an increase in systemic phosphate levels due to high phosphate diet uptake (Antoniucci et al., 2006) or decreased renal phosphate excretion, as occurs in renal patients (Larsson et al., 2003).

FGF-23 effect is mediated by binding to one of the FGF receptor isoforms (FGFR1-4). FGF-23 binding to FGFR requires the presence of a co-factor due to FGF-23's low affinity for all FGFRs (Yu et al., 2005). The FGFR1 co-factor in the kidney is the transmembrane protein Klotho (Kurosu and Kuroo, 2009), which reveals the importance of Klotho expression for FGF-23 phosphaturic effects. All organs with FGFR and Klotho expression are susceptible to FGF-23 effects. However, Urakawa et al. (2006) proposed that the only FGFR isoform capable of combining with Klotho to induce FGF-23 signaling is FGFR1, being able FGF-23 to bind to the other FGFRs in a Klotho-independent manner. In this sense, FGF-23 can also act independently of Klotho through its binding to FGFR4, as occurs in Klotho-free organs such as the heart (Faul et al., 2011; Grabner et al., 2015). In renal patients, renal excretion of phosphates decreases due to the reduction of renal Klotho expression, increasing serum phosphate levels and stimulating a maintained pathological synthesis of FGF-23 (Gutiérrez et al., 2008). In fact, renal patients present extremely high serum FGF23 levels compared to healthy people. These levels increase as renal function declines (Isakova et al., 2020), reaching the highest levels in patients undergoing dialysis (see Figure $\mathbf{1}$ and Table 1). Serum FGF-23 levels increase from $\sim 40 \mathrm{pg} / \mathrm{mL}$ in healthy subjects to $\sim 200 \mathrm{pg} / \mathrm{mL}$ in AKI patients and stage 1 CKD patients. Throughout CKD progression, serum FGF-23 continues to increase due to the progressive loss of renal function, reaching levels 20 -fold higher than those described in the healthy population. It is important to note that FGF-23 remains at similar values in the early stages of CKD (CKD1-3), while the increment of FGF-23 is greater from stage 4 CKD to ESRD. The highest serum FGF-23 levels are found in those renal patients undergoing dialysis treatment, with values above $2,000 \mathrm{pg} / \mathrm{mL}$. The phosphaturic effect of FGF-23 tries to protect against the deleterious actions of increased serum phosphates aggravated by renal dysfunction. However, it is impossible to efficiently remove phosphates from blood in advanced-stage CKD and in dialysis patients. As a result, serum FGF-23 levels are necessarily up to 1,000 times higher in these patients than among healthy people (Wolf, 2012), and these enormous FGF-23 levels can have deleterious pathological consequences on off-target organs.

Recent studies have evidenced adverse effects of FGF-23 on the heart. In this sense, elevated serum FGF-23 levels have been associated with cardiovascular events in early CKD patients (Isakova et al., 2011; Ix et al., 2012) and are also related to increased all-cause and cardiovascular mortality (Ärnlöv et al., 2013), especially in ESRD patients (Scialla et al., 2014) but also in the general population (De Jong et al., 2021). It has been observed that renal patients who experience faster elevations of FGF-23 serum levels tend to have a higher risk of death (Isakova et al., 2018). Increased serum FGF-23 levels have also been associated with increased incidence of AF (Seiler et al., 2011; Mathew et al., 2014), LVH (Faul et al., 2011), HF (Ix et al., 2012), and mortality (Isakova et al., 2011) in a concentration-dependent manner in renal patients. Therefore, the prognostic value of high FGF-23 serum levels for predicting all-cause and cardiovascular mortality has been proposed in several clinical studies and meta-analyses in renal patients and especially ESRD dialysis (Gutiérrez et al., 2008; Isakova et al., 2011; Ix et al., 2012; Ärnlöv et al., 2013).

Faul et al. (2011) first noted that the pro-hypertrophic effect of FGF-23 is FGFR-dependent and mediated by the phospholipase $\mathrm{C}$ (PLC) $\gamma$-calcineurin-nuclear factor of activated T cells (NFAT). 


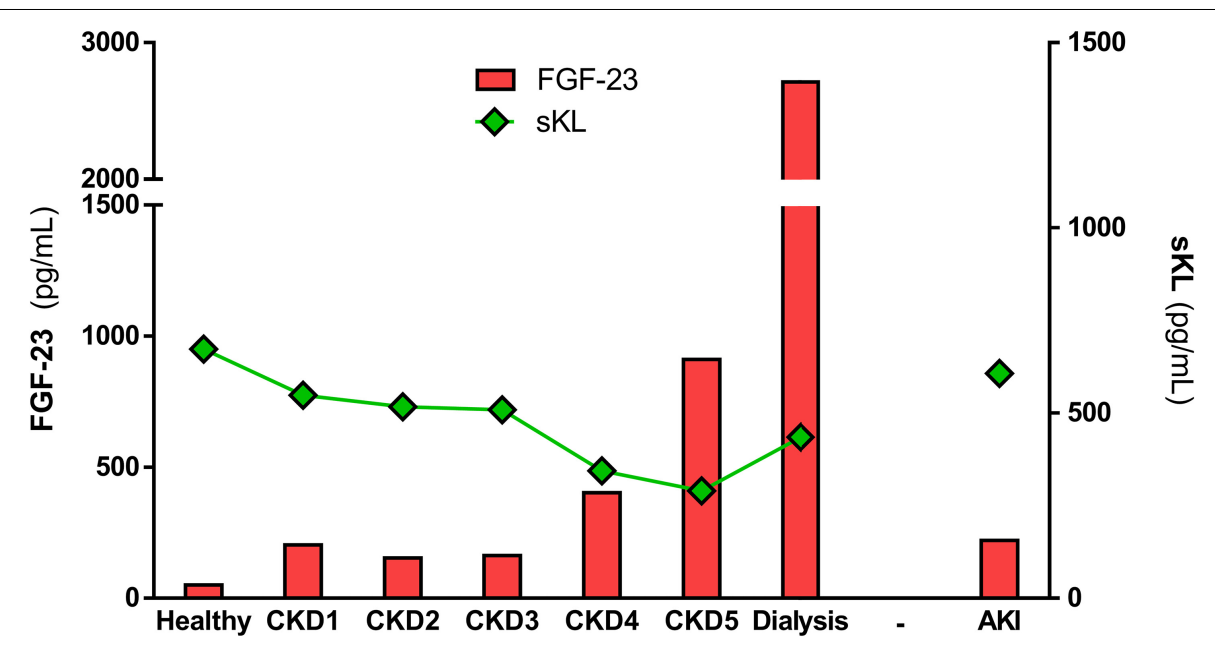

FIGURE 1 | Mean values of FGF-23 and SKL in healthy population and alongside renal disease. The graph represents the mean values of serum FGF-23 and sKL levels described in the different renal cohorts included in Tables 1, 2.

TABLE 1 | Mean values of serum FGF-23 levels measured in pg/mL in healthy subjects and different renal patients.

\begin{tabular}{|c|c|c|}
\hline Population & FGF-23 values $(\mathrm{pg} / \mathrm{mL})$ & References \\
\hline Healthy & $42.7 \pm 18.6$ & $\begin{array}{l}\text { Yamazaki et al., 2010; Chathoth et al., 2015; Leaf et al., 2018; Neyra et al., 2019; Rodríguez-Ortiz et al., 2020; Shardell } \\
\text { et al., 2020; Matei et al., 2021; Salam et al., } 2021\end{array}$ \\
\hline AKI & $220.9 \pm 126.8$ & Leaf et al., 2018; Rygasiewicz et al., 2018; Fayed et al., 2019; Neyra et al., 2019 \\
\hline CKD1 & $203.5 \pm 346.0$ & Evenepoel et al., 2010; Kim et al., 2013; lio et al., 2019; Khodeir et al., 2019; Bielesz et al., 2020 \\
\hline CKD2 & $153.3 \pm 296.0$ & $\begin{array}{l}\text { Evenepoel et al., 2010; Kanbay et al., 2010; Kim et al., 2013; lio et al., 2019; Khodeir et al., 2019; Bielesz et al., 2020; } \\
\text { Shardell et al., 2020; Kritmetapak et al., } 2021\end{array}$ \\
\hline CKD3 & $162.7 \pm 264.8$ & $\begin{array}{l}\text { Evenepoel et al., 2010; Kim et al., 2013; Chathoth et al., 2015; Bouma-de Krijger et al., 2019; Khodeir et al., } 2019 \text {; lio et al., } \\
\text { 2019; Ramalho et al., 2019; Bielesz et al., 2020; D'Arrigo et al., 2020; Hughes-Austin et al., 2020; Jovanovich et al., 2021; } \\
\text { Kritmetapak et al., } 2021\end{array}$ \\
\hline CKD4 & $402.3 \pm 537.1$ & $\begin{array}{l}\text { Kim et al., 2013; Chathoth et al., 2015; Khodeir et al., 2019; lio et al., 2019; Bielesz et al., 2020; Chen et al., 2021; } \\
\text { Kritmetapak et al., } 2021\end{array}$ \\
\hline CKD5 & $911.0 \pm 640.4$ & $\begin{array}{l}\text { Kim et al., 2013; Chathoth et al., 2015; Khodeir et al., 2019; lio et al., 2019; Bielesz et al., 2020; Chen et al., 2021; } \\
\text { Kritmetapak et al., 2021; Salam et al., } 2021\end{array}$ \\
\hline Dialysis & $2713.0 \pm 1294.0$ & $\begin{array}{l}\text { Fukasawa et al., 2014; Lima et al., 2014; Otani-Takei et al., 2015; Damasiewicz et al., 2018; Kulicki et al., 2019; Chan et al., } \\
\text { 2020; Takashi et al., } 2020\end{array}$ \\
\hline
\end{tabular}

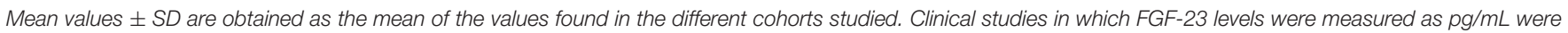
included in this table. These studies were carried out on diabetic or cardiovascular patient cohorts, with pediatric cohorts excluded.

At the experimental level, pro-hypertrophic FGF-23 actions were found to occur in cardiomyocytes in an FGFR-dependent manner (Böckmann et al., 2019) but Klotho-independently (Faul et al., 2011). Andrukhova et al. (2014) proposed that FGF-23 increases sodium renal uptake Klotho-dependently, producing a volume overload and hypertension and finally leading to the development of LVH. By contrast, other authors have postulated that FGF23 is not able to induce cardiac hypertrophy in the absence of hyperphosphatemia conditions (Liu et al., 2018). Moreover, it is not yet clear whether FGF-23 is the cause or a consequence of LVH. Thus, it has been demonstrated that transgenic mice that constitutively express active calcineurin A, the key pathway involved in pathological LVH, showed a significant increment in serum FGF-23 levels without any alteration of renal function (Matsui et al., 2018). Cardiomyocyte expression of FGF-23 under stress conditions has also been demonstrated by other authors. Specifically, it has been probed in different rodent models that the expression of FGF-23 is increased not only in bones but also in the heart as consequence of a myocardial infraction induction (Andrukhova et al., 2015). Furthermore, the expression of FGF-23 in cardiomyocytes has been observed to be increased by oncostatin $\mathrm{M}$, a major mediator of cardiac remodeling (Richter et al., 2015).

Several studies have additionally shown a direct effect of FGF23 on cardiac function. Different authors have demonstrated a relationship between high FGF-23 levels and predisposition to arrhythmia. First, it was found that high levels of FGF-23 were related to AF (Mathew et al., 2014; Lind et al., 2017). A prospective study found a strong association between FGF-23 and incident and prevalent AF in renal patients with mildto-severe CKD (Mehta et al., 2016). This relationship was corroborated in experimental studies where the atrial immortal cell line HL-1 was incubated, with a high concentration (25 $\mathrm{ng} / \mathrm{mL}$ ) of FGF-23, inducing intracellular $\mathrm{Ca}^{2+}$ mishandling 
related to a pro-arrhythmogenic behavior (Kao et al., 2014). At the ventricular level, recent studies have demonstrated that FGF-23 is able to rapidly induce in vivo arrhythmic events by increasing the prevalence of premature ventricular contractions in healthy mice (Navarro-García et al., 2019). At the cellular level, an acute exposure to elevated FGF-23 concentration $(100 \mathrm{ng} / \mathrm{mL}$ ) has also been demonstrated to induce a pro-arrhythmogenic phenotype in isolated ventricular adult cardiomyocytes (Navarro-García et al., 2019). The increased incidence of pro-arrhythmogenic events in cardiac cells might be a consequence of the $\mathrm{Ca}^{2+}$ mishandling observed in cardiomyocytes exposed to high concentrations of FGF-23. In this work, FGF-23 effect on cardiomyocyte function is also shown to be FGFR-dependent. However, unlike the pro-hypertrophic effect, FGF-23-induced cardiomyocyte dysfunction is calmodulin kinase type II-dependent and independent of PLC $\gamma$ (NavarroGarcía et al., 2019). In this sense, it is important to note that FGF-23 has been related to LV dysfunction even in the absence of LVH (Seiler et al., 2011), suggesting that FGF-23 might be activating different intracellular pathways on cardiomyocytes, likely depending on its concentration and exposure time. Furthermore, in the CKD mouse model of 5/6 nephrectomy which shows high serum FGF-23 but normal phosphate levels, cardiac dysfunction developed without any sign of cardiac hypertrophy (Navarro-García et al., 2020). Furthermore, recent works have proposed FGF-23, independently of phosphate levels, as one of the main factor responsible for the cardiac function alterations described in CKD patients (Isakova et al., 2018). All of this evidence proposes FGF-23 as a potential candidate to interconnect cardiac and renal systems, suggesting that it may be an important contributor to the cardiac burden experienced by renal patients.

\section{Klotho}

Klotho is a protein mainly expressed in kidneys although it is also expressed in other organs such as the brain, pituitary gland, and ovaries (Kuro-o et al., 1997). There are two membrane Klotho isoforms, $\alpha$-Klotho and $\beta$-Klotho. $\alpha$-Klotho is the one that acts as the FGFR cofactor in the kidney (Urakawa et al., 2006). $\alpha$-Klotho is mainly expressed in the distal tubules where phosphate reabsorption takes place (Kurosu et al., 2005). Thus, $\alpha$-Klotho plays an important role in phosphate reabsorption in the kidney (Myrvang, 2012). $\alpha$-Klotho binds to FGFR1 in the kidney through a receptor-binding arm that forms a complex with a groove in which FGF-23 fits with the N-terminal domain oriented toward FGFR1 and the C-terminal domain toward $\alpha$-Klotho (Kuro-o, 2019). Membrane $\alpha$-Klotho can be cleaved by secretases (ADAM10 and ADAM17) that release a soluble form of Klotho, named soluble Klotho or sKL (Chen et al., 2007). sKL functions as an endocrine factor for a widespread variety of surface glycoproteins, such as ionic channels, and growth factor receptors, such as insulin-like receptors involved in stress resistance (Wang and Sun, 2009) and aging control (Kuro-o, 2009), highlighting its implication in the aging process.

$\alpha$-Klotho expression, and consequently sKL levels, are closely associated with kidney function. Several authors have shown that serum $\alpha$-Klotho levels decrease as renal disease progresses (see
Figure 1 and Table 2). Serum levels of sKL decrease from $\sim 670$ $\mathrm{pg} / \mathrm{mL}$ in healthy subjects to $\sim 300 \mathrm{pg} / \mathrm{mL}$ in ESRD patients. A small decrease of sKL values has also been found in AKI or CKD1 patients. As CKD progresses, sKL levels continue to decline quickly from the early stages of the disease onward until they reach values close to $\sim 280 \mathrm{pg} / \mathrm{mL}$ in CKD5 patients. Dialysis patients show values around $\sim 400 \mathrm{pg} / \mathrm{mL}$, which is still significantly lower than the healthy population. The higher sKL levels in dialysis-treated patients might be due to these groups of patients comprising patients with different renal failure etiologies, meaning that some of them reach dialysis without passing through the five stages of CKD. On the other hand, it is well known that renal $\alpha$-Klotho expression declines with aging. Indeed, the reduced expression of $\alpha$-Klotho is implicated in agerelated CKD development (Zeng et al., 2016). Furthermore, it has been demonstrated that higher levels of sKL are associated with a lower risk of declining kidney function (Drew et al., 2017). The role of $\alpha$-Klotho in aging has been demonstrated in experimental animal models, as Klotho-deficient mice present reduced lifespan (Kuro-o et al., 1997) while mice overexpressing $\alpha$-Klotho exhibited a longer mean lifespan (Kurosu et al., 2005). Among $\alpha$-Klotho anti-aging effects, it is important to remark on the reduction of senescence in response to oxidative stress (Kim et al., 2019), an increment of cell survival in experimental uremia, and a protection against inflammation by decreasing expression and nuclear translocation of NFKB (Guo et al., 2018).

Some experimental studies have demonstrated that the absence of Klotho is associated with cardiovascular pathologies (Hu et al., 2011; Chen et al., 2016) and even with early unexpected death in mice (Takeshita et al., 2004). Klotho-deficient mice are characterized by hyperphosphatemia and enormously increased levels of serum FGF-23 (Kuro-o et al., 1997). Klotho-deficient mice also exhibit cardiac hypertrophy (Leifheit-Nestler et al., 2018) and cardiac dysfunction (Navarro-García et al., 2020). By contrast, Klotho-overexpressing mice are protected from cardiac dysfunction when CKD is induced (Navarro-García et al., 2020). However, it is unclear whether the cardiac alterations described in the absence of Klotho are a direct consequence of Klotho deficiency or induced by subsequent enormously increased serum FGF-23. At the clinical level, no association has been found yet between Klotho levels and cardiovascular mortality in the general population (Brandenburg et al., 2015), although it has been proposed Klotho as a predictor of all-cause mortality in the elderly population (Semba et al., 2011). In this line, a lower risk of cardiovascular disease development was found in elderly people with higher Klotho levels, even after adjusting for traditional cardiovascular risk factors (Semba et al., 2011). Moreover, lower sKL levels have been associated with increased mortality and cardiovascular events independently from other MBD-related factors in ESRD patients (Memmos et al., 2019). Several studies have also investigated the use of Klotho as therapeutic strategy owing its cardioprotective role. At the experimental level, cardiac dysfunction associated with reduced sKL serum levels has been prevented with enhanced sKL availability (Hui et al., 2017; Navarro-García et al., 2020). However, the mechanism through which sKL protects the heart remains unknown. It has been suggested that sKL protects the heart through the downregulation 
TABLE 2 | Mean values of serum-soluble Klotho levels measured in pg/mL in healthy subjects and different renal patients.

\begin{tabular}{lcl}
\hline Population & sKL levels $\mathbf{( p g} / \mathbf{m L})$ & References \\
\hline Healthy & $672.8 \pm 78.7$ & Yamazaki et al., 2010; Yokoyama et al., 2012; Shardell et al., 2020; Yin et al., 2020; Zbroch et al., 2020; Salam et al., 2021 \\
AKI & $606.7 \pm 55.3$ & Kim et al., 2016; Seibert et al., 2017 \\
CKD1 & $547.8 \pm 75.9$ & Kim et al., 2013; Khodeir et al., 2019; Bielesz et al., 2020; Yin et al., 2020 \\
CKD2 & $517.1 \pm 104.0$ & Kim et al., 2013; Seiler et al., 2014; Khodeir et al., 2019; Bielesz et al., 2020; Shardell et al., 2020; Yin et al., 2020 \\
CKD3 & $508.9 \pm 157.9$ & Kim et al., 2013; Seiler et al., 2014; Khodeir et al., 2019; Bielesz et al., 2020; Hughes-Austin et al., 2020; Yin et al., 2020 \\
CKD4 & $343.5 \pm 141.4$ & Kim et al., 2013; Seiler et al., 2014; Khodeir et al., 2019; Bielesz et al., 2020; Yin et al., 2020; Chen et al., 2021 \\
CKD5 & $289.2 \pm 160.6$ & Kim et al., 2013; Khodeir et al., 2019; Bielesz et al., 2020; Yin et al., 2020; Chen et al., 2021 \\
Dialysis & $435.0 \pm 111.8$ & Yokoyama et al., 2012; Buiten et al., 2014; Fukasawa et al., 2014; Lima et al., 2014; Nowak et al., 2014; Otani-Takei et al., \\
& & $\begin{array}{l}\text { 2015; Desbiens et al., 2018; Valenzuela et al., 2019; Chan et al., 2020; Nakamura et al., 2020; Zbroch et al., 2020; Pizzarelli } \\
\text { et al., 2021 }\end{array}$
\end{tabular}

Mean values are obtained as the mean \pm SD of the values found in the different cohorts studied. Those studies carried on diabetic or cardiovascular patient cohorts, with pediatric cohorts excluded.

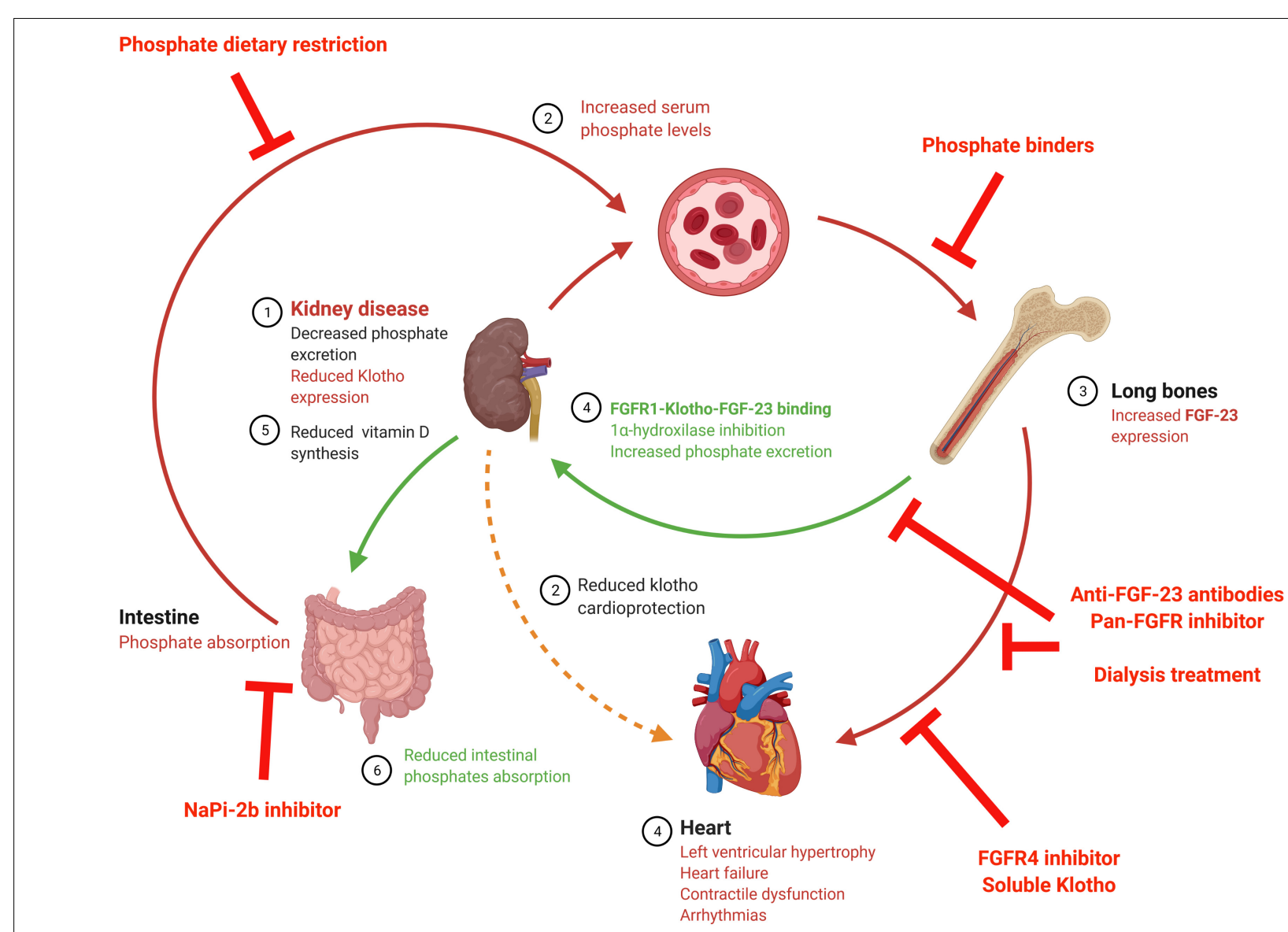

FIGURE 2 | Schematic diagram of possible strategies to impede deleterious FGF-23 cardiac effects. The above illustration shows the FGF-23 synthesis stimuli and FGF-23 effects, along with the different treatments studied to avoid FGF-23 cardiac effects. FGFR, Fibroblast growth factor receptor; FGF-23, fibroblast growth factor 23; NaPi-2b, Sodium-Phosphate cotransporter 2b.

of the Transient Receptor Potential Cation Channel Subfamily C Member 6 (TRPC6) associated with HF (Xie et al., 2015; Hu et al., 2017; Han et al., 2020). Furthermore, it has been demonstrated that sKL prevents cardiac hypertrophy by direct regulation of several ion channels (Xie et al., 2012), or even in the context of uremic cardiomyopathy (Xie et al., 2015; Hu et al., 2017). Interestingly, it has been recently described that FGF-23-induced cardiac hypertrophy is also attenuated by sKL in mice. Han et al. (2020) proposed a possible switch on the signaling pathways induced by FGF-23 in the presence of sKL. The presence of Klotho might induce a change in the intracellular pathways activated in cardiomyocytes by FGF-23. Thus, in the absence of Klotho, FGF-23 activates the PLC-NFAT intracellular pathway, while when Klotho is available, the intracellular pathway activated 
TABLE 3 | Therapeutic strategies directed to decreased serum FGF-23 levels or to avoid FGF-23 effects.

\begin{tabular}{|c|c|c|c|c|c|}
\hline Treatment & Study & Specie & Renal disease & Serum FGF-23 & Outcomes \\
\hline \multicolumn{6}{|c|}{ Decrease FGF-23 synthesis } \\
\hline \multirow[t]{5}{*}{ Reduced Pi intake } & $\begin{array}{l}\text { Chang et al., } \\
2017\end{array}$ & Human & Early CKD & Unchanged & No changes in albuminuria \\
\hline & Sigrist et al., 2013 & Human & CKD & Reduced & \\
\hline & Xie et al., 2015 & Mouse & CKD (5/6 Nfx) & Unchanged & No prevention of cardiac hypertrophy \\
\hline & Finch et al., 2013 & Rat & CKD (5/6 Nfx) & Reduced & $\begin{array}{l}\text { Reduced aortic calcification Partially reduced cardiac fibrosis } \\
\text { Prevented cardiomyocyte hypertrophy }\end{array}$ \\
\hline & Duayer et al., 2021 & Rat & CKD (5/6 Nfx) & Reduced & Improved kidney function \\
\hline \multirow[t]{9}{*}{ Pi binders } & Ruggiero et al., 2019 & Human & CKD & Unchanged & $\begin{array}{l}\text { Unchanged Klotho levels Ameliorated inflammation Improved } \\
\text { dyslipidemia }\end{array}$ \\
\hline & Mason et al., 2021 & Human & CKD (stage 3-4) & Reduced & Decreased inflammatory levels Improved vascular calcification \\
\hline & Ketteler et al., 2019 & Human & ESRD & Reduced & Improved bone metabolism \\
\hline & Chue et al., 2013 & Human & CKD (stage 3) & Unchanged & $\begin{array}{l}\text { No changes in left ventricular mass, systolic and diastolic } \\
\text { functions, or arterial stiffness }\end{array}$ \\
\hline & Toussaint et al., 2020 & Human & CKD (stage 3b-4) & Unchanged & $\begin{array}{l}\text { No amelioration of arterial stiffness Non-improved of aortic } \\
\text { calcification }\end{array}$ \\
\hline & $\begin{array}{l}\text { Ghorbanihaghjo et al., } \\
2018\end{array}$ & Rat & CKD (adenine diet) & Reduced & \\
\hline & Finch et al., 2013 & Rat & CKD (5/6 Nfx) & Reduced & $\begin{array}{l}\text { Non-reduced aortic calcification Reduced mortality } \\
\text { Non-reduced cardiac fibrosis Increased cardiomyocyte area }\end{array}$ \\
\hline & Neven et al., 2020 & Rat & CKD (adenine diet) & Reduced & Improved kidney function Decreased bone fibrosis \\
\hline & Wu-Wong et al., 2016 & Rat & CKD (5/6 Nfx) & Reduced & Reduced aorta calcification \\
\hline \multirow[t]{3}{*}{ NPT2 inhibitiion } & Rao et al., 2014 & Human & CKD & Unchanged & \\
\hline & Ix et al., 2019 & Human & CKD (stage 3b-4) & Unchanged & \\
\hline & Thomas et al., 2019 & Mouse & CKD (5/6 Nfx $)$ & $\begin{array}{l}\text { Increased in the } \\
\text { long term }\end{array}$ & Reduced PTH \\
\hline \multicolumn{6}{|c|}{ Increased FGF-23 clearance } \\
\hline \multirow[t]{2}{*}{ Dialysis } & Kawabata et al., 2020 & Human & ESRD & Reduced & Unchanged Klotho levels \\
\hline & Tiong et al., 2021 & Human & ESRD & Reduced & \\
\hline \multicolumn{6}{|l|}{ FGF-23 neutralization } \\
\hline \multirow[t]{2}{*}{ Anti-FGF-23 antibody } & Sun et al., 2015 & Mouse & CKD (5/6 Nfx) & Reduced & Improved bone quality \\
\hline & Shalhoub et al., 2012 & Rat & CKD (High Pi diet) & Unchanged & Increased aortic calcification Increased mortality \\
\hline \multicolumn{6}{|l|}{ Blockage of FGFR } \\
\hline \multirow[t]{2}{*}{ Pan-FGFR antibody } & Di Marco et al., 2014 & Rat & CKD $(5 / 6 \mathrm{Nfx})$ & Unchanged & Improved cardiac structure and function \\
\hline & Faul et al., 2011 & Rat & CKD (5/6 Nfx) & Unchanged & Attenuation of cardiac hypertrophy \\
\hline Anti-FGFR4 antibody & Grabner et al., 2017 & Rat & CKD (5/6 Nfx) & Unchanged & Reduced cardiac hypertrophy \\
\hline \multicolumn{6}{|l|}{ Klotho treatment } \\
\hline \multirow[t]{2}{*}{ Recombinant Klotho } & $\begin{array}{l}\text { Navarro-García et al., } \\
2020\end{array}$ & Mouse & CKD (5/6 Nfx) & Unchanged & Prevention of cardiac dysfunction \\
\hline & Suassuna et al., 2020 & Rat & $\operatorname{CKD}(5 / 6 \mathrm{Nfx})$ & Unchanged & Prevented cardiac hypertrophy and fibrosis \\
\hline $\begin{array}{l}\text { Transgenic Klotho } \\
\text { expression }\end{array}$ & Xie et al., 2015 & Mouse & CKD & Unchanged & Reduced cardiac hypertrophy and fibrosis \\
\hline
\end{tabular}

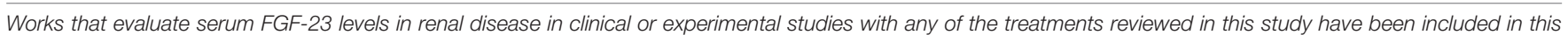
table.

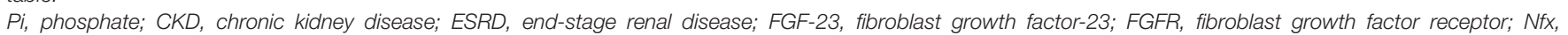
nephrectomy; NPT2, sodium-phosphate cotransporter 2.

by FGF-23 is the ERK pathway. Furthermore, enhanced Klotho availability has also been shown to protect against FGF-23induced cardiac dysfunction in vitro (Navarro-García et al., 2019) and even in CKD mice (Navarro-García et al., 2020). Increased Klotho availability has additionally been found to protect against cardiovascular alterations developed in mice with reduced Klotho expression (Lim et al., 2012; Chen et al., 2016).

In conclusion, the cardioprotective role of Klotho, although promising, remains poorly understood. Some authors have proposed different mechanism for Klotho cardioprotection: (i) sKL would be able to bind to an unknown receptor activating an intracellular pathways that impede FGF-23 effects; (ii) in cells where the FGF-23 effect is Klotho-independent (as occurs in cardiomyocytes), the presence of sKL would block FGF23 signaling once it binds to the FGFR, probably the FGFR4 isoform; or (iii) sKL might function as a soluble "lure" for FGF23, binding to FGF-23 at the circulatory level and impeding its subsequent interaction with FGFR (Grabner and Faul, 2016; 


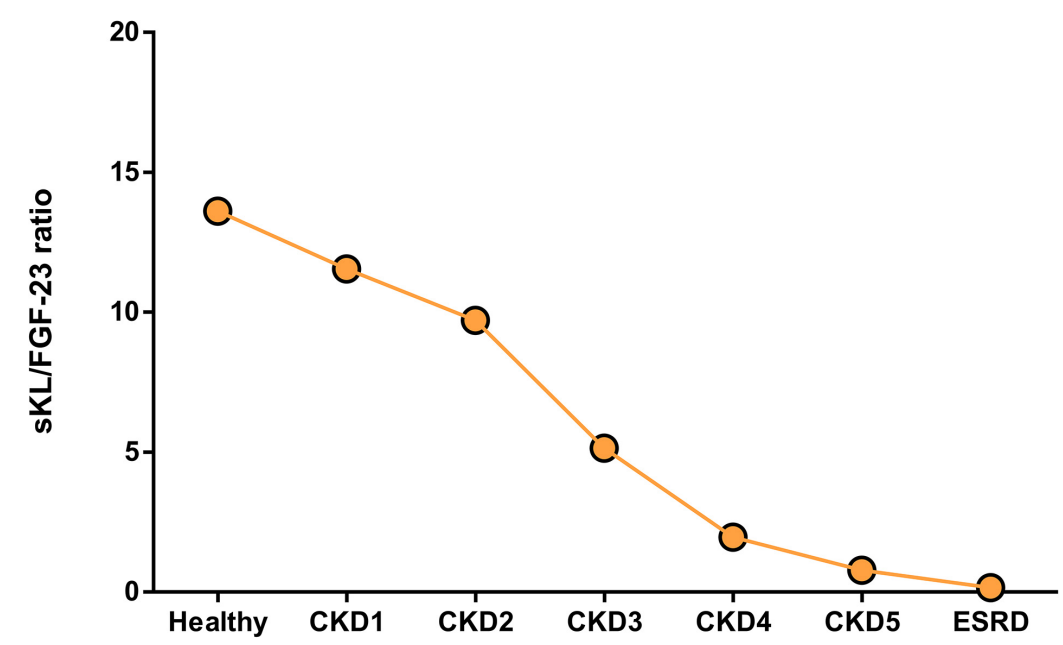

FIGURE 3 | Ratio between serum SKL and FGF-23 levels in healthy population and renal patients alongside CKD and dialysis. Ratio was obtained between sKL and FGF-23 from the same cohort of patients included in Tables 1, 2; only studies where both values of these markers were reported were used for this graph.

Navarro-García et al., 2019). More studies are needed to clarify Klotho's actions and its relationship with FGF-23 in the heart from a functional perspective and especially in a uremic cardiomyopathy setting.

\section{FIBROBLAST GROWTH FACTOR-23-KLOTHO AXIS AS THERAPEUTIC TARGET IN RENAL DISEASE}

As reviewed recently by Verbueken and Moe (2021) there are different treatments designed to block high FGF-23 levels that vary depending on the target (see Figure $\mathbf{2}$ and Table 3 ), although not all of these are recommended for use with renal patients. The first target is to decrease FGF-23 production. FGF23 production is lowered by decreasing serum phosphate levels by reducing dietary phosphate intake (Calvo et al., 2019), a crucial recommended management in renal patients. It has been shown that phosphate dietary restrictions reduce FGF-23 serum load in CKD patients (Sigrist et al., 2013; Chang et al., 2017), although no effect has been observed in the healthy population (Larsson et al., 2003). At experimental level, dietary phosphate restriction has been also demonstrated to reduced systemic FGF-23 levels in 5/6 nephrectomized rats with a significant improvement of kidney function (Duayer et al., 2021) and prevention of cardiac fibrosis and hypertrophy (Finch et al., 2013). However, Xie et al. (2015) has described no effect on serum FGF-23 levels and no prevention of cardiac hypertrophy after dietary phosphate restriction. Serum phosphate load can also be reduced clinically using phosphate binders, a typical therapy in renal patients. Several clinical and experimental studies have demonstrated that pathological synthesis of FGF-23 can be prevented with a phosphate binder in uremic conditions (Ketteler et al., 2019; Neven et al., 2020; Mason et al., 2021) although other studies has no probed any changes in serum FGF-23 levels after the use of these treatments
(Chue et al., 2013; Ruggiero et al., 2019; Toussaint et al., 2020). When used in experimental animal models of CKD, phosphate binder reduced serum FGF-23 levels (Ghorbanihaghjo et al., 2018) with a significant reduction in aortic calcification (Finch et al., 2013; Wu-Wong et al., 2016). Moreover, serum phosphate levels can be controlled through the reduction of intestinal phosphate absorption by inhibiting the NaPi-2b cotransporter. In this sense, nicotinamide and niacin, both $\mathrm{NaPi}-2 \mathrm{~b}$ inhibitors, have been demonstrated to reduce FGF-23 serum levels in a controlled trial of ESRD (Liu et al., 2020). However, this effect has not been found in clinical trial with stage 3 CKD patients treated with niacin (Rao et al., 2014) or nicotinamide (Ix et al., 2019). Furthermore, in an experimental mouse model of CKD, serum FGF-23 levels increased in long term after the use of this inhibitors (Thomas et al., 2019).

Increased FGF-23 serum levels can be also corrected by increasing FGF-23 clearance. In this sense, it has been described that dialysis reduced FGF-23 levels (Kawabata et al., 2020; Tiong et al., 2021), possibly as a consequence of reduction in phosphate serum levels (Chan et al., 2020). In this case, FGF-23 reduction might be a direct effect of dialysis, as different FGF-23 reductions have been found depending on the type of hemodialysis in use (Patrier et al., 2013). It is important to note that FGF-23 levels in dialysis-dependent renal patients are extremely high despite the dialysis process, and that these patients are usually treated with phosphate binders and under dietary phosphate restrictions. Consequently, recent approaches are exploring other mechanisms to block the deleterious effects of FGF-23 in renal patients. To this aim, some researchers have studied experimentally the effect of FGF-23-neutralizing antibodies. In spite of reducing serum FGF-23 levels improving bone quality in CKD mice (Sun et al., 2015), anti-FGF-23 antibodies treatment was found to significantly augment phosphate levels, vascular calcification, and death risk in an experimental CKD model (Shalhoub et al., 2012). A complete FGF-23 function inhibition would also block its phosphaturic action, which is still important 
when renal function is not completely lost. Thus, completely blocking the effects of FGF-23 would increase phosphate levels in early stage renal patients, likely with undesirable consequences. It is probably for this reason that no studies of anti-FGF-23 antibodies have carried out in renal patients thus far to date.

Another proposed strategy is the blockage of deleterious offtarget FGF-23 action (such as that in the heart) by specific FGFR inhibitors. In this line, a pan-FGFR inhibitor has been shown to impede cardiac hypertrophy (Faul et al., 2011; Di Marco et al., 2014) and dysfunction (Navarro-García et al., 2019) induced by FGF-23. However, the inhibition of all FGFR would also block FGF-23 phosphaturic actions in the kidney, mediated by FGFR1, which may in turn increase serum phosphate levels promoting the synthesis of FGF-23. Since FGFR4 has been proposed as the necessary mediator of cardiac FGF-23 effects (Grabner et al., $2015,2017)$ a better strategy to prevent the deleterious cardiac effects of FGF-23 would be the use of specific FGFR4 blockers. The use of a specific FGFR4 inhibitor would avoid the inhibition of the physiologic phosphaturic effect of FGF-23 on the kidney mediated by FGFR1. However, no FGFR inhibitors have been used in humans with renal disease so far.

As discussed above there are different approaches to reduce FGF-23 actions preventing deleterious actions on the heart. However, all of them could block the actions of FGF-23, not only the pathological but also de physiological phosphaturic action. The loss of the FGF-23 phosphaturic action would increase even more the serum phosphate levels in those renal patients with remaining kidney function that would be an important side effect to be considered in those treatments. New therapies to prevent cardiac effect of FGF-23 without impeding FGF23 phosphaturic effect are needed. Thus, the use of sKL as a therapeutic strategy to block the deleterious effects of FGF-23 on the heart without altering its physiological phosphaturic function is becoming increasingly important nowadays. In this sense, Law et al. (2020) has reviewed recently different approaches to increase Klotho levels as a possible therapeutic strategy to prevent cardiac alterations described under uremic conditions. Several experimental studies have demonstrated that sKL treatment prevents heart alterations found following renal dysfunction. Thus, sKL treatment was found to prevent FGF-23-induced cardiac hypertrophy (Han et al., 2020; Suassuna et al., 2020) and dysfunction (Navarro-García et al., 2020) in experimental CKD models. In this line, Klotho overexpression has been shown to prevent cardiac alterations in a uremic milieu (Navarro-García et al., 2020). Nevertheless, some authors propose that Klotho's cardioprotective role is FGF-23- and phosphate-independent (Xie et al., 2015). Thus, maintaining adequate Klotho levels might represent a new therapeutic strategy to avoid the cardiac dysfunction described in renal patients, including those cardiac effects mediated directly by FGF-23, while at the same time guaranteeing its physiological phosphaturic action. Studies on the inhibition of FGF-23 effects on the heart in the presence of sKL remark on the importance of the role of not only FGF23 but also sKL in the heart. In the present review, we propose the balance between FGF-23 and sKL availability as a new prognostic tool for renal patients (Figure 3). Decreased Klotho availability together with increased systemic FGF-23 levels should be taken into consideration as a warning sign for increased risk of deleterious cardiac prognosis in renal patients. Whether a ratio sKL/FGF-23 is used as a tool to characterize the balance between both mineral components in renal patients, we can observe a significant reduction of this ratio from the early stages of CKD. In early CKD, the reduction of sKL/FGF-23 ratio occurs mainly due to the reduction of sKL values, as FGF-23 values are higher than in the healthy population but similar from CKD1 to CKD3. However, from CKD4 onward, the reduced sKL/FGF-23 must be the consequence of the highly increased serum FGF23 levels in these patients. The sKL/FGF-23 ratio could be used as a tool to choose an adequate treatment that impedes FGF23 side effects on organs other than the kidney, such as the heart. Thus, in those CKD stages where the misbalance is the result of decreased sKL levels, it would be useful to increase sKL values; exogenous Klotho administration could be an adequate option under these circumstances. However, in advanced CKD stages where the FGF-23 levels are enormously high, treatment directed at reducing FGF-23 synthesis could be more adequate for renal patients.

\section{CONCLUDING REMARKS AND FUTURE PERSPECTIVES}

In conclusion, there is growing evidence to support the important role played by the FGF-23-Klotho axis in the CRS. Thus, FGF23 and Klotho should be considered not only as important biomarkers in renal patients to evaluate cardiovascular events and mortality risks, but also as a therapeutic target. Many human and experimental studies have demonstrated that high levels of FGF-23 or low levels of sKL are linked with cardiovascular risk and mortality, although few of these have considered the balance between them as a possible therapeutic target. Recent studies have shown that increased Klotho availability might protect the heart even in high FGF-23 conditions with and without hyperphosphatemia and with no renal modifications, indicating that Klotho may be the best therapeutic target to prevent FGF-23's deleterious effects on the heart identified thus far. However, more studies are needed to analyze more adequate strategies to block FGF-23 action and enhance Klotho availability, especially in humans.

\section{AUTHOR CONTRIBUTIONS}

JAN-G and GR-H designed, conceptualized the review, and wrote the first draft of the manuscript. LG-L, MF-V, and LR participated in different sections of the review. All authors revised and approved the final version of the review.

\section{FUNDING}

The authors acknowledge the support from the Instituto de Salud Carlos III (PI17/01093, PI20/00763, and CPII20/00022) and cofunded by the European Regional Development Fund (Fondos FEDER), and partially from the SENEFRO Foundation. 


\section{REFERENCES}

Ahmed, A., Rich, M. W., Sanders, P. W., Perry, G. J., Bakris, G. L., Zile, M. R., et al. (2007). Chronic kidney disease associated mortality in diastolic versus systolic heart failure: a propensity matched study. Am. J. Cardiol. 99, 393-398. doi: 10.1016/j.amjcard.2006.08.042

Anderson, J. L., May, H. T., Horne, B. D., Bair, T. L., Hall, N. L., Carlquist, J. F., et al. (2010). Relation of vitamin D deficiency to cardiovascular risk factors, disease status, and incident events in a general healthcare population. Am. J. Cardiol. 106, 963-968. doi: 10.1016/j.amjcard.2010.05.027

Andrukhova, O., Slavic, S., Odörfer, K. I., and Erben, R. G. (2015). Experimental Myocardial Infarction Upregulates Circulating Fibroblast Growth Factor-23. J. Bone Miner. Res. 30, 1831-1839. doi: 10.1002/jbmr.2527

Andrukhova, O., Slavic, S., Smorodchenko, A., Zeitz, U., Shalhoub, V., Lanske, B., et al. (2014). FGF23 regulates renal sodium handling and blood pressure. EMBO Mol. Med. 6, 744-759.

Anis, K. H., Pober, D., and Rosas, S. E. (2020). Vitamin D Analogues and Coronary Calcification in CKD Stages 3 and 4: a Randomized Controlled Trial of Calcitriol Versus Paricalcitol. Kidney Med. 2, 450-458. doi: 10.1016/j.xkme. 2020.05.009

Antlanger, M., Aschauer, S., Kopecky, C., Hecking, M., Kovarik, J. J., Werzowa, J., et al. (2017). Heart Failure with Preserved and Reduced Ejection Fraction in Hemodialysis Patients: prevalence, Disease Prediction and Prognosis. Kidney Blood Press Res. 42, 165-176. doi: 10.1159/000473868

Antoniucci, D. M., Yamashita, T., and Portale, A. A. (2006). Dietary phosphorus regulates serum fibroblast growth factor-23 concentrations in healthy men. J. Clin. Endocrinol. Metab. 91, 3144-3149. doi: 10.1210/jc.2006-0021

Ärnlöv, J., Carlsson, A. C., Sundström, J., Ingelsson, E., Larsson, A., Lind, L., et al. (2013). Higher fibroblast growth factor-23 increases the risk of all-cause and cardiovascular mortality in the community. Kidney Int. 83, 160-166.

Bacchetta, J., Bernardor, J., Garnier, C., Naud, C., and Ranchin, B. (2020). Hyperphosphatemia and Chronic Kidney Disease: a Major Daily Concern Both in Adults and in Children. Calcif. Tissue Int. 108, 116-127. doi: 10.1007/s00223020-00665-8

Bailey, G. L., Hampers, C. L., and Merrill, J. P. (1967). Reversible cardiomyopathy in uremia. Trans. Am. Soc. Artif. Intern. Organs 13, 263-270.

Banerjee, D. (2016). Sudden cardiac death in haemodialysis: clinical epidemiology and mechanisms. J. Electrocardiol. 49, 843-847.

Bansal, N., Katz, R., Robinson-Cohen, C., Odden, M. C., Dalrymple, L., Shlipak, M. G., et al. (2017). Absolute Rates of Heart Failure, Coronary Heart Disease, and Stroke in Chronic Kidney Disease: an Analysis of 3 Community-Based Cohort Studies. JAMA Cardiol. 2, 314-318. doi: 10.1001/jamacardio.2016.4652

Bielesz, B., Reiter, T., Hammerle, F. P., Winnicki, W., Bojic, M., Gleiss, A., et al. (2020). The Role of Iron and Erythropoietin in the Association of Fibroblast Growth Factor 23 with Anemia in Chronic Kidney Disease in Humans. J. Clin. Med. 9:2640.

Block, G. A., Klassen, P. S., Lazarus, J. M., Ofsthun, N., Lowrie, E. G., and Chertow, G. M. (2004). Mineral metabolism, mortality, and morbidity in maintenance hemodialysis. J. Am. Soc. Nephrol. 15, 2208-2218.

Böckmann, I., Lischka, J., Richter, B., Deppe, J., Rahn, A., Fischer, D. C., et al. (2019). FGF23-Mediated Activation of Local RAAS Promotes Cardiac Hypertrophy and Fibrosis. Int. J. Mol. Sci. 20:4634. doi: 10.3390/ijms20184634

Bodyak, N., Ayus, J. C., Achinger, S., Shivalingappa, V., Ke, Q., Chen, Y. S., et al. (2007). Activated vitamin D attenuates left ventricular abnormalities induced by dietary sodium in Dahl salt-sensitive animals. Proc. Natl. Acad. Sci. U. S. A. 104, 16810-16815. doi: 10.1073/pnas.0611202104

Bouma-de Krijger, A., Van Ittersum, F. J., Hoekstra, T., Ter Wee, P. M., and Vervloet, M. G. (2019). Short-term effects of sevelamer-carbonate on fibroblast growth factor 23 and pulse wave velocity in patients with normophosphataemic chronic kidney disease Stage 3. Clin. Kidney J. 12, 678-685. doi: 10.1093/ckj/ sfz027

Brandenburg, V. M., Kleber, M. E., Vervloet, M. G., Larsson, T. E., Tomaschitz, A., Pilz, S., et al. (2015). Soluble klotho and mortality: the Ludwigshafen Risk and Cardiovascular Health Study. Atherosclerosis 242, 483-489. doi: 10.1016/j. atherosclerosis.2015.08.017

Buiten, M. S., De Bie, M. K., Bouma-De Krijger, A., Van Dam, B., Dekker, F. W., Jukema, J. W., et al. (2014). Soluble Klotho is not independently associated with cardiovascular disease in a population of dialysis patients. BMC Nephrol. 15:197. doi: 10.1186/1471-2369-15-197

Calvo, M. S., Sherman, R. A., and Uribarri, J. (2019). Dietary Phosphate and the Forgotten Kidney Patient: a Critical Need for FDA Regulatory Action. Am. J. Kidney Dis. 73, 542-551. doi: 10.1053/j.ajkd.2018.11.004

Chan, C. T., Kaysen, G. A., Beck, G. J., Li, M., Lo, J. C., Rocco, M. V., et al. (2020). The effect of frequent hemodialysis on matrix metalloproteinases, their tissue inhibitors, and FGF23: implications for blood pressure and left ventricular mass modification in the Frequent Hemodialysis Network trials. Hemodial. Int. 24, 162-174. doi: 10.1111/hdi.12807

Chang, A. R., and Grams, M. E. (2014). Serum phosphorus and mortality in the Third National Health and Nutrition Examination Survey (NHANES III): effect modification by fasting. Am. J. Kidney Dis. 64, 567-573. doi: 10.1053/j.ajkd. 2014.04.028

Chang, A. R., Miller, E. R., Anderson, C. A., Juraschek, S. P., Moser, M., White, K., et al. (2017). Phosphorus Additives and Albuminuria in Early Stages of Ckd: a Randomized Controlled Trial. Am. J. Kidney Dis. 69, 200-209. doi: 10.1053/j.ajkd.2016.08.029

Chathoth, S., Al-Mueilo, S., Cyrus, C., Vatte, C., Al-Nafaie, A., Al-Ali, R., et al. (2015). Elevated Fibroblast Growth Factor 23 Concentration: prediction of Mortality among Chronic Kidney Disease Patients. Cardiorenal. Med. 6, 73-82.

Chen, C. D., Podvin, S., Gillespie, E., Leeman, S. E., and Abraham, C. R. (2007). Insulin stimulates the cleavage and release of the extracellular domain of Klotho by ADAM10 and ADAM17. Proc. Natl. Acad. Sci. U. S. A. 104, 19796-19801. doi: 10.1073/pnas.0709805104

Chen, J., Lin, Y., and Sun, Z. (2016). Deficiency in the anti-aging gene Klotho promotes aortic valve fibrosis through Ampk $\alpha$-mediated activation of RUNX2. Aging Cell. 15, 853-860. doi: 10.1111/acel.12494

Chen, Y., Chen, Y. X., Huang, C., Duan, Z. B., and Xu, C. Y. (2021). The Clinical Value of Klotho and FGF23 in Cardiac Valve Calcification Among Patients with Chronic Kidney Disease. Int. J. Gen. Med. 14, 857-866. doi: 10.2147/IJGM. S299197

Christakos, S., Dhawan, P., Ajibade, D., Benn, B. S., Feng, J., and Joshi, S. S. (2010). Mechanisms involved in vitamin D mediated intestinal calcium absorption and in non-classical actions of vitamin D. J. Steroid. Biochem. Mol. Biol. 121, 183-187. doi: 10.1016/j.jsbmb.2010.03.005

Christov, M., Waikar, S. S., Pereira, R. C., Havasi, A., Leaf, D. E., Goltzman, D., et al. (2013). Plasma FGF23 levels increase rapidly after acute kidney injury. Kidney Int. 84, 776-785. doi: 10.1038/ki.2013.150

Chue, C. D., Townend, J. N., Moody, W. E., Zehnder, D., Wall, N. A., Harper, L., et al. (2013). Cardiovascular effects of sevelamer in stage 3 CKD. J. Am. Soc. Nephrol. 24, 842-852. doi: 10.1681/asn.2012070719

Coll, M., Ferrer-Costa, C., Pich, S., Allegue, C., Rodrigo, E., Fernández-Fresnedo, G., et al. (2018). Role of genetic and electrolyte abnormalities in prolonged QTC interval and sudden cardiac death in end-stage renal disease patients. PLoS One 13:e0200756. doi: 10.1371/journal.pone.0200756

Cozzolino, M., Ciceri, P., Galassi, A., Mangano, M., Carugo, S., Capelli, I., et al. (2019). The Key Role of Phosphate on Vascular Calcification. Toxins 11:213. doi: $10.3390 /$ toxins 11040213

Curione, M., Amato, S., Di Bona, S., Petramala, L., Cotesta, D., and Letizia, C. (2010). Parathyroidectomy erase increased myocardial electrical vulnerability in patients with primary hyperparathyroidism. Int. J. Cardiol. 141, 201-202. doi: 10.1016/j.ijcard.2008.11.067

Damasiewicz, M. J., Lu, Z. X., Kerr, P. G., and Polkinghorne, K. R. (2018). The stability and variability of serum and plasma fibroblast growth factor-23 levels in a haemodialysis cohort. BMC Nephrol. 19:325. doi: 10.1186/s12882-018-1127-7

D’Arrigo, G., Pizzini, P., Cutrupi, S., Tripepi, R., Tripepi, G., Mallamaci, F., et al. (2020). FGF23 and the PTH response to paricalcitol in chronic kidney disease. Eur. J. Clin. Invest. 50, e13196.

de Jager, D. J., Grootendorst, D. C., Jager, K. J., Van Dijk, P. C., Tomas, L. M., Ansell, D., et al. (2009). Cardiovascular and noncardiovascular mortality among patients starting dialysis. JAMA 302, 1782-1789. doi: 10.1001/jama.2009. 1488

De Jong, M. A., Eisenga, M. F., Van Ballegooijen, A. J., Beulens, J. W. J., Vervloet, M. G., Navis, G., et al. (2021). Fibroblast growth factor 23 and new-onset chronic kidney disease in the general population: the Prevention of Renal and Vascular Endstage Disease (Prevend) study. Nephrol. Dial. Transplant. 36, 121-128. doi: $10.1093 /$ ndt/gfz266 
Desbiens, L. C., Sidibé, A., Ung, R. V., Fortier, C., Munger, M., Wang, Y. P., et al. (2018). FGF23-klotho axis, bone fractures, and arterial stiffness in dialysis: a case-control study. Osteoporos Int. 29, 2345-2353. doi: 10.1007/s00198-0184598-2

Di Lullo, L., Reeves, P. B., Bellasi, A., and Ronco, C. (2019). Cardiorenal Syndrome in Acute Kidney Injury. Semin. Nephrol. 39, 31-40.

Di Marco, G. S., Reuter, S., Kentrup, D., Grabner, A., Amaral, A. P., Fobker, M., et al. (2014). Treatment of established left ventricular hypertrophy with fibroblast growth factor receptor blockade in an animal model of CKD. Nephrol. Dial. Transplant. 29, 2028-2035. doi: 10.1093/ndt/gfu190

Drew, D. A., Katz, R., Kritchevsky, S., Ix, J., Shlipak, M., Gutiérrez, O. M., et al. (2017). Association between Soluble Klotho and Change in Kidney Function: the Health Aging and Body Composition Study. J. Am. Soc. Nephrol. 28, 1859-1866. doi: 10.1681/ASN.2016080828

Duayer, I. F., Duque, E. J., Fujihara, C. K., De Oliveira, I. B., Dos Reis, L. M., Machado, F. G., et al. (2021). The Protein-Independent Role of Phosphate in the Progression of Chronic Kidney Disease. Toxins 13:503. doi: 10.3390/ toxins 13070503

Evenepoel, P., Meijers, B., Viaene, L., Bammens, B., Claes, K., Kuypers, D., et al. (2010). Fibroblast growth factor-23 in early chronic kidney disease: additional support in favor of a phosphate-centric paradigm for the pathogenesis of secondary hyperparathyroidism. Clin. J. Am. Soc. Nephrol. 5, 1268-1276. doi: 10.2215/CJN.08241109

Faul, C., Amaral, A. P., Oskouei, B., Hu, M. C., Sloan, A., Isakova, T., et al. (2011). FGF23 induces left ventricular hypertrophy. J. Clin. Invest. 121, 4393-4408.

Fayed, A., Radwan, W. A., Amin, M., and Gamal, A. (2019). Prediction of mortality and need for renal replacement therapy in patients of acute kidney injury using fibroblast growth factor 23. Saudi. J. Kidney Dis. Transpl. 30, 1044-1051. doi: 10.4103/1319-2442.270259

Finch, J. L., Lee, D. H., Liapis, H., Ritter, C., Zhang, S., Suarez, E., et al. (2013). Phosphate restriction significantly reduces mortality in uremic rats with established vascular calcification. Kidney Int. 84, 1145-1153. doi: 10.1038/ki. 2013.213

Fox, B. M., Gil, H. W., Kirkbride-Romeo, L., Bagchi, R. A., Wennersten, S. A., Haefner, K. R., et al. (2019). Metabolomics assessment reveals oxidative stress and altered energy production in the heart after ischemic acute kidney injury in mice. Kidney Int. 95, 590-610. doi: 10.1016/j.kint.2018.10.020

Fukasawa, H., Ishigaki, S., Kinoshita-Katahashi, N., Niwa, H., Yasuda, H., Kumagai, H., et al. (2014). Plasma levels of fibroblast growth factor-23 are associated with muscle mass in haemodialysis patients. Nephrology 19, 784-790. doi: $10.1111 /$ nep. 12333

Gammelager, H., Christiansen, C. F., Johansen, M. B., Tønnesen, E., Jespersen, B., and Sørensen, H. T. (2014). Three-year risk of cardiovascular disease among intensive care patients with acute kidney injury: a population-based cohort study. Crit. Care 18:492. doi: 10.1186/s13054-014-0492-2

Gansevoort, R. T., Correa-Rotter, R., Hemmelgarn, B. R., Jafar, T. H., Heerspink, H. J., Mann, J. F., et al. (2013). Chronic kidney disease and cardiovascular risk: epidemiology, mechanisms, and prevention. Lancet 382, 339-352.

Genovesi, S., Rossi, E., Nava, M., Riva, H., De Franceschi, S., Fabbrini, P., et al. (2013). A case series of chronic haemodialysis patients: mortality, sudden death, and QT interval. Europace 15, 1025-1033. doi: 10.1093/europace/eu s412

Ghorbanihaghjo, A., Argani, H., Golmohamadi, Z., Rashtchizadeh, N., Abbasi, M. M., Bargahi, N., et al. (2018). Linkage of Fibroblast Growth Factor 23 and Phosphate in Serum: Phosphate and Fibroblast Growth Factor 23 Reduction by Increasing Dose of Sevelamer. J. Bone Metab. 25, 153-159. doi: 10.11005/jbm. 2018.25.3.153

Go, A. S., Chertow, G. M., Fan, D., Mcculloch, C. E., and Hsu, C. Y. (2004). Chronic kidney disease and the risks of death, cardiovascular events, and hospitalization. N. Engl. J. Med. 351, 1296-1305. doi: 10.1056/nejmoa04 1031

Go, A. S., Hsu, C. Y., Yang, J., Tan, T. C., Zheng, S., Ordonez, J. D., et al. (2018). Acute Kidney Injury and Risk of Heart Failure and Atherosclerotic Events. Clin. J. Am. Soc. Nephrol. 13, 833-841. doi: 10.2215/cjn.12591117

Gotsman, I., Shauer, A., Zwas, D. R., Hellman, Y., Keren, A., Lotan, C., et al. (2012). Vitamin D deficiency is a predictor of reduced survival in patients with heart failure; vitamin D supplementation improves outcome. Eur. J. Heart Fail. 14, 357-366. doi: 10.1093/eurjhf/hfr175
Grabner, A., Amaral, A. P., Schramm, K., Singh, S., Sloan, A., Yanucil, C., et al. (2015). Activation of Cardiac Fibroblast Growth Factor Receptor 4 Causes Left Ventricular Hypertrophy. Cell. Metab. 22, 1020-1032.

Grabner, A., and Faul, C. (2016). The role of fibroblast growth factor 23 and Klotho in uremic cardiomyopathy. Curr. Opin. Nephrol. Hypertens 25, 314-324. doi: $10.1097 / \mathrm{mnh} .0000000000000231$

Grabner, A., Schramm, K., Silswal, N., Hendrix, M., Yanucil, C., Czaya, B., et al. (2017). Fgf23/Fgfr4-mediated left ventricular hypertrophy is reversible. Sci. Rep. 7:1993. doi: 10.1038/s41598-017-02068-6

Guo, Y., Zhuang, X., Huang, Z., Zou, J., Yang, D., Hu, X., et al. (2018). Klotho protects the heart from hyperglycemia-induced injury by inactivating Ros and Nf-кB-mediated inflammation both in vitro and in vivo. Biochim. Biophys. Acta Mol. Basis Dis. 1864, 238-251. doi: 10.1016/j.bbadis.2017.09.029

Gutiérrez, O. M., Mannstadt, M., Isakova, T., Rauh-Hain, J. A., Tamez, H., Shah, A., et al. (2008). Fibroblast growth factor 23 and mortality among patients undergoing hemodialysis. N. Engl. J. Med. 359, 584-592.

Han, X., Cai, C., Xiao, Z., and Quarles, L. D. (2020). Fgf23 induced left ventricular hypertrophy mediated by Fgfr4 signaling in the myocardium is attenuated by soluble Klotho in mice. J. Mol. Cell Cardiol. 138, 66-74. doi: 10.1016/j.yjmcc. 2019.11.149

Harnett, J. D., Foley, R. N., Kent, G. M., Barre, P. E., Murray, D., and Parfrey, P. S. (1995). Congestive heart failure in dialysis patients: prevalence, incidence, prognosis and risk factors. Kidney Int. 47, 884-890. doi: 10.1038/ki.1995.132

House, A. A., Wanner, C., Sarnak, M. J., Piña, I. L., Mcintyre, C. W., Komenda, P., et al. (2019). Heart failure in chronic kidney disease: conclusions from a Kidney Disease: Improving Global Outcomes (KDIGO) Controversies Conference. Kidney Int. 95, 1304-1317.

Hsieh, H. L., Hsu, S. C., Cheng, H. S., Chen, C. Y., Huang, W. C., Sue, Y. M., et al. (2020). The influence of atrial fibrillation on the mortality of incident Esrd patients undergoing maintenance hemodialysis. PLoS One 15:e0228405. doi: 10.1371/journal.pone.0228405

Hu, M. C., Shi, M., Gillings, N., Flores, B., Takahashi, M., Kuro-O, M., et al. (2017). Recombinant $\alpha$-Klotho may be prophylactic and therapeutic for acute to chronic kidney disease progression and uremic cardiomyopathy. Kidney Int. 91, 1104-1114. doi: 10.1016/j.kint.2016.10.034

Hu, M. C., Shi, M., Zhang, J., Quiñones, H., Griffith, C., Kuro-O, M., et al. (2011). Klotho deficiency causes vascular calcification in chronic kidney disease. J. Am. Soc. Nephrol. 22, 124-136. doi: 10.1681/asn.2009121311

Hughes-Austin, J. M., Katz, R., Semba, R. D., Kritchevsky, S. B., Bauer, D. C., Sarnak, M. J., et al. (2020). Biomarkers of Bone Turnover Identify Subsets of Chronic Kidney Disease Patients at Higher Risk for Fracture. J. Clin. Endocrinol. Metab. 105, e2903-e2911. doi: 10.1210/clinem/dgaa317

Hui, H., Zhai, Y., Ao, L., Cleveland, J. C., Liu, H., Fullerton, D. A., et al (2017). Klotho suppresses the inflammatory responses and ameliorates cardiac dysfunction in aging endotoxemic mice. Oncotarget 8, 15663-15676. doi: 10. 18632/oncotarget.14933

Iio, K., Kabata, D., Iio, R., Imai, Y., Hatanaka, M., Omori, H., et al. (2019). Parathyroid hormone and premature thymus ageing in patients with chronic kidney disease. Sci. Rep. 9:813. doi: 10.1038/s41598-018-37511-9

Isakova, T., Cai, X., Lee, J., Mehta, R., Zhang, X., Yang, W., et al. (2020). Longitudinal Evolution of Markers of Mineral Metabolism in Patients With CKD: the Chronic Renal Insufficiency Cohort (CRIC) Study. Am. J. Kidney Dis. 75, 235-244. doi: 10.1053/j.ajkd.2019.07.022

Isakova, T., Cai, X., Lee, J., Xie, D., Wang, X., Mehta, R., et al. (2018). Longitudinal Fgf23 Trajectories and Mortality in Patients with CKD. J. Am. Soc. Nephrol. 29, 579-590. doi: 10.1681/ASN.2017070772

Isakova, T., Xie, H., Yang, W., Xie, D., Anderson, A. H., Scialla, J., et al. (2011). Fibroblast growth factor 23 and risks of mortality and end-stage renal disease in patients with chronic kidney disease. JAMA 305, 2432-2439. doi: 10.1001/ jama.2011.826

Ix, J. H., Isakova, T., Larive, B., Raphael, K. L., Raj, D. S., Cheung, A. K., et al. (2019) Effects of Nicotinamide and Lanthanum Carbonate on Serum Phosphate and Fibroblast Growth Factor-23 in CKD: the Combine Trial. J. Am. Soc. Nephrol. 30, 1096-1108. doi: 10.1681/ASN.2018101058

Ix, J. H., Katz, R., Kestenbaum, B. R., De Boer, I. H., Chonchol, M., Mukamal, K. J., et al. (2012). Fibroblast growth factor-23 and death, heart failure, and cardiovascular events in community-living individuals: CHS (Cardiovascular Health Study). J. Am. Coll. Cardiol. 60, 200-207. doi: 10.1016/j.jacc.2012.03.040 
Jovanovich, A., Ginsberg, C., You, Z., Katz, R., Ambrosius, W. T., Berlowitz, D., et al. (2021). FGF23, Frailty, and Falls in Sprint. J. Am. Geriatr. Soc. 69, 467-473. doi: $10.1111 /$ jgs.16895

Jung, S. Y., Kwon, J., Park, S., Jhee, J. H., Yun, H. R., Kim, H., et al. (2018). Phosphate is a potential biomarker of disease severity and predicts adverse outcomes in acute kidney injury patients undergoing continuous renal replacement therapy. PLoS One 13:e0191290. doi: 10.1371/journal.pone. 0191290

Kanbay, M., Nicoleta, M., Selcoki, Y., Ikizek, M., Aydin, M., Eryonucu, B., et al. (2010). Fibroblast growth factor 23 and fetuin A are independent predictors for the coronary artery disease extent in mild chronic kidney disease. Clin. J. Am. Soc. Nephrol. 5, 1780-1786. doi: 10.2215/CJN.02560310

Kao, Y. H., Chen, Y. C., Lin, Y. K., Shiu, R. J., Chao, T. F., Chen, S. A., et al. (2014). FGF-23 dysregulates calcium homeostasis and electrophysiological properties in Hl-1 atrial cells. Eur. J. Clin. Invest 44, 795-801. doi: 10.1111/eci.12296

Katai, K., Miyamoto, K., Kishida, S., Segawa, H., Nii, T., Tanaka, H., et al. (1999). Regulation of intestinal $\mathrm{Na}+$-dependent phosphate co-transporters by a lowphosphate diet and 1,25-dihydroxyvitamin D3. Biochem. J. 343, 705-712. doi: 10.1042/bj3430705

Kawabata, C., Komaba, H., Ishida, H., Nakagawa, Y., Hamano, N., Koizumi, M. et al. (2020). Changes in Fibroblast Growth Factor 23 and Soluble Klotho Levels After Hemodialysis Initiation. Kidney Med. 2, 59-67. doi: 10.1016/j.xkme.2019. 09.007

Ketteler, M., Sprague, S. M., Covic, A. C., Rastogi, A., Spinowitz, B., Rakov, V., et al. (2019). Effects of sucroferric oxyhydroxide and sevelamer carbonate on chronic kidney disease-mineral bone disorder parameters in dialysis patients. Nephrol. Dial. Transplant. 34, 1163-1170. doi: 10.1093/ndt/gf y127

Khodeir, S. A., Okda, H. I., and Abdalal, H. M. (2019). Clinical significance of fibroblast growth factor-23 and soluble alpha klotho in different stages of chronic kidney disease. Saudi. J. Kidney Dis. Transpl. 30, 108-118. doi: 10.4103/ 1319-2442.252900

Khouzam, R. N., Dishmon, D. A., Farah, V., Flax, S. D., Carbone, L. D., and Weber, K. T. (2006). Secondary hyperparathyroidism in patients with untreated and treated congestive heart failure. Am. J. Med. Sci. 331, 30-34. doi: 10.1097/ 00000441-200601000-00009

Kim, A. J., Ro, H., Kim, H., Chang, J. H., Lee, H. H., Chung, W., et al. (2016). Klotho and S100A8/A9 as Discriminative Markers between Pre-Renal and Intrinsic Acute Kidney Injury. PLoS One 11:e0147255. doi: 10.1371/journal. pone. 0147255

Kim, E. D., Soliman, E. Z., Coresh, J., Matsushita, K., and Chen, L. Y. (2021). TwoWeek Burden of Arrhythmias across Ckd Severity in a Large Community-Based Cohort: the Aric Study. J. Am. Soc. Nephrol. 32, 629-638. doi: 10.1681/ASN. 2020030301

Kim, H. R., Nam, B. Y., Kim, D. W., Kang, M. W., Han, J. H., Lee, M. J., et al. (2013). Circulating $\alpha$-klotho levels in $\mathrm{Ckd}$ and relationship to progression. Am. J. Kidney Dis. 61, 899-909. doi: 10.1053/j.ajkd.2013.0 1.024

Kim, M. G., Yang, J., Ko, Y. S., Lee, H. Y., Oh, S. W., Cho, W. Y., et al. (2019). Impact of aging on transition of acute kidney injury to chronic kidney disease. Sci. Rep. 9:18445.

Kottgen, A., Russell, S. D., Loehr, L. R., Crainiceanu, C. M., Rosamond, W. D., Chang, P. P., et al. (2007). Reduced kidney function as a risk factor for incident heart failure: the atherosclerosis risk in communities (Aric) study. J. Am. Soc. Nephrol. 18, 1307-1315. doi: 10.1681/asn.2006101159

Kritmetapak, K., Losbanos, L., Berent, T. E., Ashrafzadeh-Kian, S. L., AlgecirasSchimnich, A., Hines, J. M., et al. (2021). Hyperphosphatemia with elevated serum Pth and Fgf23, reduced 1,25(OH) $(\mathrm{OH}) 2 \mathrm{D}$ and normal FGF7 concentrations characterize patients with CKD. BMC Nephrol. 22:114. doi: 10.1186/s12882-021-02311-3

Kronenberg, H. M. (2002). Npt2a-the key to phosphate homeostasis. N. Engl. J. Med. 347, 1022-1024. doi: 10.1056/NEJMe020098

Kulicki, P., Żebrowski, P., Sokalski, A., Klatko, W., Birecka, M., Mieczkowski, M., et al. (2019). [Circulating bone turnover markers and their relationships in hemodialysis patients with vitamin D deficiency]. Wiad Lek. 72, 2202-2209.

Kuro-o, M. (2009). Klotho and aging. Biochim. Biophys. Acta 1790, 1049-1058.

Kuro-o, M. (2019). The Klotho proteins in health and disease. Nat. Rev. Nephrol. 15, 27-44. doi: 10.1038/s41581-018-0078-3
Kuro-o, M., Matsumura, Y., Aizawa, H., Kawaguchi, H., Suga, T., Utsugi, T., et al. (1997). Mutation of the mouse klotho gene leads to a syndrome resembling ageing. Nature 390, 45-51. doi: 10.1038/36285

Kurosu, H., and Kuro-o, M. (2009). The Klotho gene family as a regulator of endocrine fibroblast growth factors. Mol. Cell. Endocrinol. 299, 72-78. doi: 10.1016/j.mce.2008.10.052

Kurosu, H., Yamamoto, M., Clark, J. D., Pastor, J. V., Nandi, A., Gurnani, P., et al. (2005). Suppression of aging in mice by the hormone Klotho. Science 309, 1829-1833. doi: 10.1126/science. 1112766

Larsson, T., Nisbeth, U., Ljunggren, O., Jüppner, H., and Jonsson, K. B. (2003). Circulating concentration of Fgf-23 increases as renal function declines in patients with chronic kidney disease, but does not change in response to variation in phosphate intake in healthy volunteers. Kidney Int. 64, 2272-2279. doi: 10.1046/j.1523-1755.2003.00328.x

Law, J. P., Price, A. M., Pickup, L., Radhakrishnan, A., Weston, C., Jones, A. M., et al. (2020). Clinical Potential of Targeting Fibroblast Growth Factor-23 and $\alpha$ Klotho in the Treatment of Uremic Cardiomyopathy. J. Am. Heart Assoc. 9:e016041.

Leaf, D. E., and Christov, M. (2019). Dysregulated Mineral Metabolism in Aki. Semin. Nephrol. 39, 41-56. doi: 10.1016/j.semnephrol.2018.10.004

Leaf, D. E., Siew, E. D., Eisenga, M. F., Singh, K., Mc Causland, F. R., Srivastava, A., et al. (2018). Fibroblast Growth Factor 23 Associates with Death in Critically Ill Patients. Clin. J. Am. Soc. Nephrol. 13, 531-541. doi: 10.2215/cjn.10810917

Legrand, M., and Rossignol, P. (2020). Cardiovascular Consequences of Acute Kidney Injury. N. Engl. J. Med. 382, 2238-2247.

Leifheit-Nestler, M., Grabner, A., Hermann, L., Richter, B., Schmitz, K., Fischer, D. C., et al. (2017). Vitamin D treatment attenuates cardiac Fgf23/Fgfr4 signaling and hypertrophy in uremic rats. Nephrol. Dial. Transplant. 32, 1493 1503. doi: $10.1093 / \mathrm{ndt} / \mathrm{gfw} 454$

Leifheit-Nestler, M., Richter, B., Basaran, M., Nespor, J., Vogt, I., Alesutan, I., et al. (2018). Impact of Altered Mineral Metabolism on Pathological Cardiac Remodeling in Elevated Fibroblast Growth Factor 23. Front. Endocrinol. 9:333. doi: 10.3389/fendo.2018.00333

Lim, K., Lu, T. S., Molostvov, G., Lee, C., Lam, F. T., Zehnder, D., et al. (2012) Vascular Klotho deficiency potentiates the development of human artery calcification and mediates resistance to fibroblast growth factor 23. Circulation 125, 2243-2255. doi: 10.1161/CIRCULATIONAHA.111.053405

Lima, F., El-Husseini, A., Monier-Faugere, M. C., David, V., Mawad, H., Quarles, D., et al. (2014). Fgf-23 serum levels and bone histomorphometric results in adult patients with chronic kidney disease on dialysis. Clin. Nephrol. 82, 287-295. doi: 10.5414/CN108407

Lind, L., Sundström, J., Stenemo, M., Hagström, E., and Ärnlöv, J. (2017). Discovery of new biomarkers for atrial fibrillation using a custom-made proteomics chip. Heart 103, 377-382. doi: 10.1136/heartjnl-2016-309764

Liu, E. S., Thoonen, R., Petit, E., Yu, B., Buys, E. S., Scherrer-Crosbie, M., et al. (2018). Increased Circulating FGF23 Does Not Lead to Cardiac Hypertrophy in the Male Hyp Mouse Model of Xlh. Endocrinology 159, 2165-2172. doi: 10.1210/en.2018-00174

Liu, X. Y., Yao, J. R., Xu, R., Xu, L. X., Zhang, Y. F., Lu, S., et al. (2020). Investigation of nicotinamide as more than an anti-phosphorus drug in chronic hemodialysis patients: a single-center, double-blind, randomized, placebo-controlled trial. Ann. Transl. Med. 8, 530. doi: 10.21037/atm.2020.03.228

Madsen, S., Olgaard, K., and Ladefoged, J. (1981). Suppressive effect of 1,25dihydroxyvitamin D3 on circulating parathyroid hormone in acute renal failure. J. Clin. Endocrinol. Metab. 53, 823-827. doi: 10.1210/jcem-53-4-823

Mason, D. L., Godugu, K., Nnani, D., and Mousa, S. A. (2021). Effects of sevelamer carbonate versus calcium acetate on vascular calcification, inflammation, and endothelial dysfunction in chronic kidney disease. Clin. Transl. Sci. 2, 1-8. doi: $10.1111 /$ cts. 13151

Matei, A., Bilha, S. C., Constantinescu, D., Pavel-Tanasa, M., Cianga, P., Covic, A., et al. (2021). Body composition, adipokines, Fgf23-Klotho and bone in kidney transplantation: Is there a link? J. Nephrol. Epub online ahead of print. doi: 10.1007/s40620-021-00972-9

Mathew, J. S., Sachs, M. C., Katz, R., Patton, K. K., Heckbert, S. R., Hoofnagle, A. N., et al. (2014). Fibroblast growth factor-23 and incident atrial fibrillation: the Multi-Ethnic Study of Atherosclerosis (Mesa) and the Cardiovascular Health Study (CHS). Circulation 130, 298-307. doi: 10.1161/CIRCULATIONAHA. 113.005499 
Matsui, I., Oka, T., Kusunoki, Y., Mori, D., Hashimoto, N., Matsumoto, A., et al. (2018). Cardiac hypertrophy elevates serum levels of fibroblast growth factor 23. Kidney Int. 94, 60-71. doi: 10.1016/j.kint.2018.02.018

Matsushita, K., Coresh, J., Sang, Y., Chalmers, J., Fox, C., Guallar, E., et al. (2015). Estimated glomerular filtration rate and albuminuria for prediction of cardiovascular outcomes: a collaborative meta-analysis of individual participant data. Lancet Diabetes Endocrinol. 3, 514-525. doi: 10.1016/s2213-8587(15) 00040-6

Mehta, R., Cai, X., Lee, J., Scialla, J. J., Bansal, N., Sondheimer, J. H., et al. (2016). Association of Fibroblast Growth Factor 23 With Atrial Fibrillation in Chronic Kidney Disease, From the Chronic Renal Insufficiency Cohort Study. JAMA Cardiol. 1, 548-556. doi: 10.1001/jamacardio.2016.1445

Memmos, E., Sarafidis, P., Pateinakis, P., Tsiantoulas, A., Faitatzidou, D., Giamalis, P., et al. (2019). Soluble Klotho is associated with mortality and cardiovascular events in hemodialysis. BMC Nephrol. 20:217. doi: 10.1186/s12882-019-1391-1

Merhi, B., Shireman, T., Carpenter, M. A., Kusek, J. W., Jacques, P., Pfeffer, M., et al. (2017). Serum Phosphorus and Risk of Cardiovascular Disease, All-Cause Mortality, or Graft Failure in Kidney Transplant Recipients: An Ancillary Study of the Favorit Trial Cohort. Am. J. Kidney Dis. 70, 377-385. doi: 10.1053/j.ajkd. 2017.04.014

Middleton, R. J., Parfrey, P. S., and Foley, R. N. (2001). Left ventricular hypertrophy in the renal patient. J. Am. Soc. Nephrol. 12, 1079-1084. doi: 10.1681/asn. v1251079

Molina, P., Molina, M. D., Pallardó, L. M., Torralba, J., Escudero, V., Álvarez, L., et al. (2021). Disorders in bone-mineral parameters and the risk of death in persons with chronic kidney disease stages 4 and 5: the Pecera study. J. Nephrol. 34, 1189-1199. doi: 10.1007/s40620-020-00916-9

Moon, H., Chin, H. J., Na, K. Y., Joo, K. W., Kim, Y. S., Kim, S., et al. (2019). Hyperphosphatemia and risks of acute kidney injury, end-stage renal disease, and mortality in hospitalized patients. BMC Nephrol. 20:362. doi: 10.1186/ s12882-019-1556-y

Myrvang, H. (2012). Basic research: role of renal Klotho in mineral metabolism. Nat. Rev. Nephrol. 8:553. doi: 10.1038/nrneph.2012.174

Nakamura, K., Nagata, Y., Hiroyoshi, T., Isoyama, N., Fujikawa, K., Miura, Y., et al. (2020). The effect of lanthanum carbonate on calciprotein particles in hemodialysis patients. Clin. Exp. Nephrol. 24, 323-329. doi: 10.1007/s10157019-01832-4

Navarro-García, J. A., Delgado, C., Fernández-Velasco, M., Val-Blasco, A., Rodríguez-Sánchez, E., and Aceves-Ripoll, J. (2019). Fibroblast growth factor23 promotes rhythm alterations and contractile dysfunction in adult ventricular cardiomyocytes. Nephrol. Dial. Transplant. 34, 1864-1875. doi: 10.1093/ndt/ gfy392

Navarro-García, J. A., Fernández-Velasco, M., Delgado, C., Delgado, J. F., KuroO, M., Ruilope, L. M., et al. (2018). PTH, vitamin D, and the FGF-23-klotho axis and heart: going beyond the confines of nephrology. Eur. J. Clin. Invest. 48. Epub online ahead print. doi: 10.1111/eci.12902

Navarro-García, J. A., Rueda, A., Romero-García, T., Aceves-Ripoll, J., RodríguezSánchez, E., González-Lafuente, L., et al. (2020). Enhanced Klotho availability protects against cardiac dysfunction induced by uraemic cardiomyopathy by regulating Ca. Br. J. Pharmacol. 177, 4701-4719. doi: 10.1111/bph.15235

Naveh-Many, T., and Volovelsky, O. (2020). Parathyroid Cell Proliferation in Secondary Hyperparathyroidism of Chronic Kidney Disease. Int. J. Mol. Sci. 21:4332. doi: 10.3390/ijms21124332

Neven, E., Corremans, R., Vervaet, B. A., Funk, F., Walpen, S., Behets, G. J., et al. (2020). Renoprotective effects of sucroferric oxyhydroxide in a rat model of chronic renal failure. Nephrol. Dial. Transplant. 35, 1689-1699. doi: 10.1093/ ndt/gfaa080

Neyra, J. A., Li, X., Mescia, F., Ortiz-Soriano, V., Adams-Huet, B., Pastor, J., et al. (2019). Urine Klotho Is Lower in Critically Ill Patients With Versus Without Acute Kidney Injury and Associates With Major Adverse Kidney Events. Crit. Care Explor. 1:e0016. doi: 10.1097/cce.0000000000000016

Nowak, A., Friedrich, B., Artunc, F., Serra, A. L., Breidthardt, T., Twerenbold, R., et al. (2014). Prognostic value and link to atrial fibrillation of soluble Klotho and FGF23 in hemodialysis patients. PLoS One 9:e100688. doi: 10.1371/journal. pone. 0100688

Odutayo, A., Wong, C. X., Farkouh, M., Altman, D. G., Hopewell, S., Emdin, C. A., et al. (2017). Aki and Long-Term Risk for Cardiovascular Events and Mortality. J. Am. Soc. Nephrol. 28, 377-387. doi: 10.1681/asn.2016010105
Otani-Takei, N., Masuda, T., Akimoto, T., Honma, S., Watanabe, Y., Shiizaki, K., et al. (2015). Association between Serum Soluble Klotho Levels and Mortality in Chronic Hemodialysis Patients. Int. J. Endocrinol. 2015:406269.

Owaki, A., Inaguma, D., Aoyama, I., Inaba, S., Koide, S., Ito, E., et al. (2018). Serum phosphate level at initiation of dialysis is associated with all-cause mortality: a multicenter prospective cohort study. Ren. Fail. 40, 475-482. doi: 10.1080/ 0886022x.2018.1499530

Palmer, S. C., Hayen, A., Macaskill, P., Pellegrini, F., Craig, J. C., Elder, G. J., et al. (2011). Serum levels of phosphorus, parathyroid hormone, and calcium and risks of death and cardiovascular disease in individuals with chronic kidney disease: a systematic review and meta-analysis. JAMA 305, 1119-1127. doi: 10.1001/jama.2011.308

Patrier, L., Dupuy, A. M., Granger Vallée, A., Chalabi, L., Morena, M., Canaud, B., et al. (2013). Fgf-23 removal is improved by on-line high-efficiency hemodiafiltration compared to conventional high flux hemodialysis. J. .Nephrol 26, 342-349. doi: 10.5301/jn.5000150

Pizzarelli, F., Cantaluppi, V., Panichi, V., Toccafondi, A., Ferro, G., Farruggio, S., et al. (2021). Citrate high volume on-line hemodiafiltration modulates serum Interleukin-6 and Klotho levels: the multicenter randomized controlled study "Hephaestus". J. Nephrol. 34, 1701-1710.

Priori, S. G., Aliot, E., Blomstrom-Lundqvist, C., Bossaert, L., Breithardt, G., Brugada, P., et al. (2001). Task Force on Sudden Cardiac Death of the European Society of Cardiology. Eur. Heart J. 22, 1374-1450. doi: 10.1053/euhj.2001.2824

Ramalho, J., Petrillo, E. M., Takeichi, A. P. M., Moyses, R. M. A., and Titan, S. M. (2019). Calcitriol and Fgf-23, but neither Pth nor sclerostin, are associated with calciuria in CKD. Int. Urol. Nephrol. 51, 1823-1829. doi: 10.1007/s11255-01902215-0

Rantanen, J. M., Riahi, S., Schmidt, E. B., Johansen, M. B., Søgaard, P., and Christensen, J. H. (2020). Arrhythmias in Patients on Maintenance Dialysis: a Cross-sectional Study. Am. J. Kidney Dis. 75, 214-224. doi: 10.1053/j.ajkd.2019. 06.012

Rao, M., Steffes, M., Bostom, A., and Ix, J. H. (2014). Effect of niacin on FGF23 concentration in chronic kidney disease. Am. J. Nephrol. 39, 484-490. doi: $10.1159 / 000362424$

Richter, M., Lautze, H. J., Walther, T., Braun, T., Kostin, S., and Kubin, T. (2015). The failing heart is a major source of circulating FGF23 via oncostatin M receptor activation. J. Heart Lung Transplant. 34, 1211-1214. doi: 10.1016/j. healun.2015.06.007

Rodríguez-Ortiz, M. E., Alcalá-Díaz, J. F., Canalejo, A., Torres-Peña, J. D., GómezDelgado, F., Muñoz-Castañeda, J. R., et al. (2020). Fibroblast growth factor 23 predicts carotid atherosclerosis in individuals without kidney disease. The Cordioprev study. Eur. J. Intern. Med. 74, 79-85. doi: 10.1016/j.ejim.2019.12. 008

Ronco, C., Mccullough, P., Anker, S. D., Anand, I., Aspromonte, N., Bagshaw, S. M., et al. (2010). Cardio-renal syndromes: report from the consensus conference of the acute dialysis quality initiative. Eur. Heart J. 31, 703-711. doi: 10.1093/ eurheartj/ehp507

Rouached, M., El Kadiri Boutchich, S., Al Rifai, A. M., Garabédian, M., and Fournier, A. (2008). Prevalence of abnormal serum vitamin D, PTH, calcium, and phosphorus in patients with chronic kidney disease: results of the study to evaluate early kidney disease. Kidney Int. 74, 389-390. doi: 10.1038/ki.2008.169

Roy-Chaudhury, P., Tumlin, J. A., Koplan, B. A., Costea, A. I., Kher, V., Williamson, D., et al. (2018). Primary outcomes of the Monitoring in Dialysis Study indicate that clinically significant arrhythmias are common in hemodialysis patients and related to dialytic cycle. Kidney Int. 93, 941-951. doi: 10.1016/j.kint.2017.11.019

Ruggiero, B., Trillini, M., Tartaglione, L., Rotondi, S., Perticucci, E., Tripepi, R., et al. (2019). Effects of Sevelamer Carbonate in Patients With Ckd and Proteinuria: the Answer Randomized Trial. Am. J. Kidney Dis. 74, 338-350. doi: 10.1053/j.ajkd.2019.01.029

Ruilope, L. M., and Bakris, G. L. (2011). Renal function and target organ damage in hypertension. Eur. Heart J. 32, 1599-1604.

Ruiz-Hurtado, G., and Ruilope, L. M. (2014). Does cardiovascular protection translate into renal protection? Nat. Rev. Cardiol. 11, 742-746. doi: 10.1038/ nrcardio. 2014.97

Ruiz-Hurtado, G., Sarafidis, P., Fernández-Alfonso, M. S., Waeber, B., and Ruilope, L. M. (2016). Global cardiovascular protection in chronic kidney disease. Nat. Rev. Cardiol. 13, 603-608. doi: 10.1038/nrcardio.2016.48 
Rygasiewicz, K., Hryszko, T., Siemiatkowski, A., Brzosko, S., RydzewskaRosolowska, A., and Naumnik, B. (2018). C-terminal and intact Fgf23 in critical illness and their associations with acute kidney injury and in-hospital mortality. Cytokine 103, 15-19. doi: 10.1016/j.cyto.2017.12.024

Salam, S., Gallagher, O., Gossiel, F., Paggiosi, M., Eastell, R., and Khwaja, A. (2021). Vascular calcification relationship to vascular biomarkers and bone metabolism in advanced chronic kidney disease. Bone 143:115699.

Schefold, J. C., Filippatos, G., Hasenfuss, G., Anker, S. D., and Von Haehling, S. (2016). Heart failure and kidney dysfunction: epidemiology, mechanisms and management. Nat. Rev. Nephrol. 12, 610-623. doi: 10.1038/nrneph.2016.113

Scialla, J. J., and Wolf, M. (2014). Roles of phosphate and fibroblast growth factor 23 in cardiovascular disease. Nat. Rev. Nephrol. 10, 268-278. doi: 10.1038/nrneph. 2014.49

Scialla, J. J., Xie, H., Rahman, M., Anderson, A. H., Isakova, T., Ojo, A., et al. (2014). Fibroblast growth factor-23 and cardiovascular events in Ckd. J. Am. Soc. Nephrol. 25, 349-360.

Seibert, E., Radler, D., Ulrich, C., Hanika, S., Fiedler, R., and Girndt, M. (2017). Serum klotho levels in acute kidney injury. Clin. Nephrol. 87, 173-179. doi: $10.5414 / \mathrm{cn} 108970$

Seiler, S., Cremers, B., Rebling, N. M., Hornof, F., Jeken, J., Kersting, S., et al. (2011). The phosphatonin fibroblast growth factor 23 links calcium-phosphate metabolism with left-ventricular dysfunction and atrial fibrillation. Eur. Heart J. 32, 2688-2696. doi: 10.1093/eurheartj/ehr215

Seiler, S., Heine, G. H., and Fliser, D. (2009). Clinical relevance of Fgf-23 in chronic kidney disease. Kidney Int. Suppl. 76(Suppl. 114), S34-42. doi: 10.1038/ki.2009. 405

Seiler, S., Rogacev, K. S., Roth, H. J., Shafein, P., Emrich, I., Neuhaus, S., et al. (2014). Associations of Fgf-23 and sKlotho with cardiovascular outcomes among patients with Ckd stages 2-4. Clin. J. Am. Soc. Nephrol. 9, 1049-1058. doi: 10.2215/CJN.07870713

Semba, R. D., Cappola, A. R., Sun, K., Bandinelli, S., Dalal, M., Crasto, C., et al. (2011). Plasma klotho and mortality risk in older community-dwelling adults. J. Gerontol. A Biol. Sci. Med. Sci. 66, 794-800. doi: 10.1093/gerona/glr058

Shalhoub, V., Shatzen, E. M., Ward, S. C., Davis, J., Stevens, J., Bi, V., et al. (2012). Fgf23 neutralization improves chronic kidney disease-associated hyperparathyroidism yet increases mortality. J. Clin. Invest. 122, 2543-2553. doi: 10.1172/JCI61405

Shardell, M., Drew, D. A., Semba, R. D., Harris, T. B., Cawthon, P. M., Simonsick, E. M., et al. (2020). Plasma Soluble $\alpha$ Klotho, Serum Fibroblast Growth Factor 23, and Mobility Disability in Community-Dwelling Older Adults. J. Endocr. Soc. 4:bvz032. doi: 10.1210/jendso/bvz032

Shen, Y., Zhang, X., Li, C., Wang, X., Ye, Y., Yuan, J., et al. (2020). Pressure overload promotes cystatin $\mathrm{C}$ secretion of cardiomyocytes to regulate the Mapk signaling pathway and mediate cardiac hypertrophy. Ann. Transl. Med. 8:1514. doi: 10.21037/atm-20-7041

Sigrist, M., Tang, M., Beaulieu, M., Espino-Hernandez, G., Er, L., Djurdjev, O., et al. (2013). Responsiveness of Fgf-23 and mineral metabolism to altered dietary phosphate intake in chronic kidney disease (CKD): results of a randomized trial. Nephrol. Dial. Transplant. 28, 161-169. doi: 10.1093/ndt/gfs405

Soranno, D. E., Kirkbride-Romeo, L., Wennersten, S. A., Ding, K., Cavasin, M. A., Baker, P., et al. (2021). Acute Kidney Injury Results in Long-Term Diastolic Dysfunction That Is Prevented by Histone Deacetylase Inhibition. JACC Basic Transl. Sci. 6, 119-133. doi: 10.1016/j.jacbts.2020.11.013

Suassuna, P. G. A., Cherem, P. M., De Castro, B. B., Maquigussa, E., Cenedeze, M. A., Lovisi, J. C. M., et al. (2020). $\alpha$ Klotho attenuates cardiac hypertrophy and increases myocardial fibroblast growth factor 21 expression in uremic rats. Exp. Biol. Med. 245, 66-78. doi: 10.1177/1535370219894302

Sun, N., Guo, Y., Liu, W., Densmore, M., Shalhoub, V., Erben, R. G., et al. (2015). Fgf23 neutralization improves bone quality and osseointegration of titanium implants in chronic kidney disease mice. Sci. Rep. 5:8304. doi: 10. 1038/srep08304

Takashi, Y., Wakino, S., Minakuchi, H., Ishizu, M., Kuroda, A., Shima, H., et al. (2020). Circulating Fgf23 is not associated with cardiac dysfunction, atherosclerosis, infection or inflammation in hemodialysis patients. J. Bone Miner. Metab. 38, 70-77.

Takeshita, K., Fujimori, T., Kurotaki, Y., Honjo, H., Tsujikawa, H., Yasui, K., et al. (2004). Sinoatrial node dysfunction and early unexpected death of mice with a defect of klotho gene expression. Circulation 109, 1776-1782. doi: 10.1161/01. CIR.0000124224.48962.32
Tamayo, M., Martín-Nunes, L., Val-Blasco, A., G M-Piedras, M. J., NavarroGarcía, J. A., Lage, E., et al. (2020). Beneficial effects of paricalcitol on cardiac dysfunction and remodelling in a model of established heart failure. $\mathrm{Br}$. J. Pharmacol. 177, 3273-3290. doi: 10.1111/bph.15048

Tang, W. H., Wang, C. P., Chung, F. M., Huang, L. L., Yu, T. H., Hung, W. C., et al. (2015). Uremic retention solute indoxyl sulfate level is associated with prolonged QTC interval in early CKD patients. PLoS One 10:e0119545. doi: 10.1371/journal.pone.0119545

Thomas, L., Xue, J., Murali, S. K., Fenton, R. A., Dominguez Rieg, J. A., and Rieg, T. (2019). Pharmacological Npt2a Inhibition Causes Phosphaturia and Reduces Plasma Phosphate in Mice with Normal and Reduced Kidney Function. J. Am. Soc. Nephrol. 30, 2128-2139. doi: 10.1681/ASN.20181 21250

Tiong, M. K., Krishnasamy, R., Smith, E. R., Hutchison, C. A., Ryan, E. G., Pascoe, E. M., et al. (2021). Effect of a medium cut-off dialyzer on protein-bound uremic toxins and mineral metabolism markers in patients on hemodialysis. Hemodial. Int. Epub online ahead print. doi: 10.1111/hdi.12924

Toussaint, N. D., Pedagogos, E., Lioufas, N. M., Elder, G. J., Pascoe, E. M., Badve, S. V., et al. (2020). A Randomized Trial on the Effect of Phosphate Reduction on Vascular End Points in CKD (Improve-CKD). J. Am. Soc. Nephrol. 31, 2653-2666. doi: 10.1681/asn.2020040411

Tuegel, C., and Bansal, N. (2017). Heart failure in patients with kidney disease. Heart 103, 1848-1853. doi: 10.1136/heartjnl-2016-310794

Unger, E. D., Dubin, R. F., Deo, R., Daruwalla, V., Friedman, J. L., Medina, C., et al. (2016). Association of chronic kidney disease with abnormal cardiac mechanics and adverse outcomes in patients with heart failure and preserved ejection fraction. Eur. J. Heart Fail. 18, 103-112.

Urakawa, I., Yamazaki, Y., Shimada, T., Iijima, K., Hasegawa, H., Okawa, K., et al. (2006). Klotho converts canonical FGF receptor into a specific receptor for FGF23. Nature 444, 770-774. doi: 10.1038/nature05315

Valenzuela, P. L., Cobo, F., Diez-Vega, I., Sánchez-Hernández, R., PedreroChamizo, R., Verde-Rello, Z., et al. (2019). Physical performance, plasma S-klotho, and all-cause mortality in elderly dialysis patients: a prospective cohort study. Exp. Gerontol. 122, 123-128. doi: 10.1016/j.exger.2019.05.003

van der Velde, M., Matsushita, K., Coresh, J., Astor, B. C., Woodward, M., Levey, A., et al. (2011). Lower estimated glomerular filtration rate and higher albuminuria are associated with all-cause and cardiovascular mortality. A collaborative meta-analysis of high-risk population cohorts. Kidney Int. 79, 1341-1352.

Verbueken, D., and Moe, O. W. (2021). Strategies to lower fibroblast growth factor-23 bioactivity. Nephrol. Dial Transplant. 27:gfab012. doi: 10.1093/ndt/ gfab012

Wang, Q., Su, W., Shen, Z., and Wang, R. (2018). Correlation between Soluble. Biomed. Res. Int. 2018:9481475.

Wang, Y., and Sun, Z. (2009). Current understanding of klotho. Ageing Res. Rev. 8, 43-51. doi: 10.1016/j.arr.2008.10.002

Wannamethee, S. G., Welsh, P., Papacosta, O., Lennon, L., Whincup, P. H., and Sattar, N. (2014). Elevated parathyroid hormone, but not vitamin D deficiency, is associated with increased risk of heart failure in older men with and without cardiovascular disease. Circ. Heart Fail. 7, 732-739.

Wolf, M. (2010). Forging forward with 10 burning questions on FGF23 in kidney disease. J. Am. Soc. Nephrol. 21, 1427-1435. doi: 10.1681/ASN.2009121293

Wolf, M. (2012). Update on fibroblast growth factor 23 in chronic kidney disease. Kidney Int. 82, 737-747. doi: 10.1038/ki.2012.176

Wu-Wong, J. R., Chen, Y. W., Wong, J. T., and Wessale, J. L. (2016). Preclinical studies of VS-505: a non-absorbable highly effective phosphate binder. Br. J. Pharmacol. 173, 2278-2289. doi: 10.1111/bph.13510

Xie, J., Cha, S. K., An, S. W., Kuro-O, M., Birnbaumer, L., and Huang, C. L. (2012). Cardioprotection by Klotho through downregulation of Trpc6 channels in the mouse heart. Nat. Commun. 3:1238. doi: 10.1038/ncomms2240

Xie, J., Yoon, J., An, S. W., Kuro-O, M., and Huang, C. L. (2015). Soluble Klotho Protects against Uremic Cardiomyopathy Independently of Fibroblast Growth Factor 23 and Phosphate. J. Am. Soc. Nephrol. 26, 1150-1160.

Yamazaki, Y., Imura, A., Urakawa, I., Shimada, T., Murakami, J., Aono, Y., et al. (2010). Establishment of sandwich Elisa for soluble alpha-Klotho measurement: age-dependent change of soluble alpha-Klotho levels in healthy subjects. Biochem. Biophys. Res. Commun. 398, 513-518. doi: 10.1016/j.bbrc.2010.06.110 Yin, C., Cheng, C., Wang, J., Zhang, L., Purrunsing, Y., Yang, G., et al. (2020). The relationship between urinary kidney injury molecule-1 and blood bone 
metabolism markers in patients with chronic kidney disease. Clin. Nephrol. 93, 65-76. doi: 10.5414/CN109763

Yokoyama, K., Imura, A., Ohkido, I., Maruyama, Y., Yamazaki, Y., Hasegawa, H., et al. (2012). Serum soluble $\alpha$-klotho in hemodialysis patients. Clin. Nephrol. 77, $347-351$.

Yu, X., Ibrahimi, O. A., Goetz, R., Zhang, F., Davis, S. I., Garringer, H. J., et al. (2005). Analysis of the biochemical mechanisms for the endocrine actions of fibroblast growth factor-23. Endocrinology 146, 4647-4656. doi: 10.1210/en. 2005-0670

Zbroch, E., Bazyluk, A., Malyszko, J., Koc-Zorawska, E., Rydzewska-Rosolowska, A., Kakareko, K., et al. (2020). The Serum Concentration of Anti-Aging Proteins, Sirtuin 1 and $\alpha$ Klotho in Patients with End-Stage Kidney Disease on Maintenance Hemodialysis. Clin. Interv. Aging 15, 387-393. doi: 10.2147/CIA. S236980

Zeng, Y., Wang, P. H., Zhang, M., and Du, J. R. (2016). Aging-related renal injury and inflammation are associated with downregulation of Klotho and induction of RIG-I/NF- $\mathrm{kB}$ signaling pathway in senescence-accelerated mice. Aging Clin. Exp. Res. 28, 69-76. doi: 10.1007/s40520-015-0371-y

Zou, J., Yu, Y., Wu, P., Lin, F. J., Yao, Y., Xie, Y., et al. (2016). Serum phosphorus is related to left ventricular remodeling independent of renal function in hospitalized patients with chronic kidney disease. Int. J. Cardiol. 221, 134-140. doi: 10.1016/j.ijcard.2016.06.181

Conflict of Interest: The authors declare that the research was conducted in the absence of any commercial or financial relationships that could be construed as a potential conflict of interest.

Publisher's Note: All claims expressed in this article are solely those of the authors and do not necessarily represent those of their affiliated organizations, or those of the publisher, the editors and the reviewers. Any product that may be evaluated in this article, or claim that may be made by its manufacturer, is not guaranteed or endorsed by the publisher.

Copyright ๑ 2021 Navarro-García, González-Lafuente, Fernández-Velasco, Ruilope and Ruiz-Hurtado. This is an open-access article distributed under the terms of the Creative Commons Attribution License (CC BY). The use, distribution or reproduction in other forums is permitted, provided the original author(s) and the copyright owner(s) are credited and that the original publication in this journal is cited, in accordance with accepted academic practice. No use, distribution or reproduction is permitted which does not comply with these terms. 